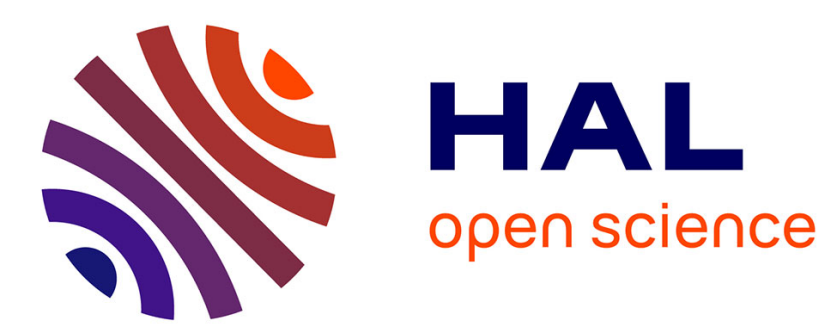

\title{
Water restriction induces behavioral fight but impairs thermoregulation in a dry-skinned ectotherm
}

David Rozen-Rechels, Simon Agostini, Arnaud Badiane, Sandrine Meylan, Jean-françois Le Galliard

\section{- To cite this version:}

David Rozen-Rechels, Simon Agostini, Arnaud Badiane, Sandrine Meylan, Jean-françois Le Galliard. Water restriction induces behavioral fight but impairs thermoregulation in a dry-skinned ectotherm. Oikos, 2020, 129 (4), pp.572-584. 10.1111/oik.06910 . hal-02480596

\section{HAL Id: hal-02480596 https://hal.science/hal-02480596}

Submitted on 19 Nov 2020

HAL is a multi-disciplinary open access archive for the deposit and dissemination of scientific research documents, whether they are published or not. The documents may come from teaching and research institutions in France or abroad, or from public or private research centers.
L'archive ouverte pluridisciplinaire HAL, est destinée au dépôt et à la diffusion de documents scientifiques de niveau recherche, publiés ou non, émanant des établissements d'enseignement et de recherche français ou étrangers, des laboratoires publics ou privés. 
1 Water restriction induces behavioral fight but impairs thermoregulation in a dry-skinned

2 ectotherm

3 Rozen-Rechels David ${ }^{1}$, Agostini Simon ${ }^{2}$, Badiane Arnaud ${ }^{1}$, Meylan Sandrine ${ }^{1,3}$, Le Galliard Jean-

4 François ${ }^{1,2}$

6 Author affiliations

$7{ }^{1}$ Sorbonne Université, CNRS, IRD, INRA, Institut d'écologie et des sciences de l'environnement (IEES), 4 Place

8 Jussieu, 75252 Paris Cedex 5, France

$9{ }^{2}$ Centre de recherche en écologie expérimentale et prédictive (CEREEP-Ecotron IleDeFrance), Département de

10 biologie, Ecole normale supérieure, CNRS, PSL University, 77140 Saint-Pierre-lès-Nemours, France.

$11{ }^{3}$ Sorbonne Université, ESPE de Paris, 10 rue Molitor, 75016 Paris, France

12

13 Corresponding author: David Rozen-Rechels, david.rozen-rechels@normalesup.org

14 Running title: Behavioral responses to water restriction

15 Keywords: body temperature; water availability; activity; micro-habitat selection; dehydration;

16 non-avian reptiles

17

18 


\section{Abstract}

20 1. Behavioral fight responses to desiccation risk are important to predict the vulnerability of

21 terrestrial animals to climate change and yet, they have received little attention so far. In terrestrial

22 ectotherms, behavioral regulation of the water balance (i.e., hydroregulation) is likely to be plastic

23 and may trade-off with thermoregulation behavior because water loss rates are generally higher in

24 warmer environments and body temperatures.

25 2. When low water availability and heat stress cause physiological dehydration, we expect to

26 highlight a shift to behavioral water-conservation strategies including changes in activity patterns,

27 microhabitat selection and thermoregulation strategies.

28 3. Here, we compared the behavior of adult common lizards (Zootoca vivipara) in indoor arenas

29 that either had a permanent access to water or underwent a one-week long experimental water

30 restriction.

31 4. Water-restricted lizards reduced their behavioral activity, selected more often cooler and wetter

32 refuges during daytime, and performed less accurate thermoregulation than control lizards. The

33 activity of water-restricted gravid females shifted towards the cooler and wetter early hours of the

34 day. In addition, they had lower body temperatures and preferred lower body temperatures at the

35 end of the experiment (i.e., thermal depression). Water-restricted lizards suffered from a mild

36 physiological dehydration, water-restricted females had lower mass change compared to control

37 ones, and water-restricted males lost weight. Heat stress was simulated every second day, which led

38 to a range of heat avoidance and water conservation strategies independent from water restriction.

39 5. Altogether, these results confirm that chronic water restriction and dehydration induce responses

40 towards water conservation that conflict with thermoregulation accuracy. 


\section{Introduction}

44 Behavioral plasticity is critical for organisms to cope with both acute and chronic changes in

45 environmental conditions, such as the short-term effects of extreme weather events and long-term

46 consequences of ongoing climate change (Beever et al., 2017; Wong \& Candolin, 2015). In the last

47 two decades, a growing number of ecological studies investigated how changes in thermal quality

48 of the environment (Row \& Blouin-Demers, 2006; Sears et al., 2016), food availability (Long et al.,

49 2014; Manenti et al. 2013), and predation pressures (McGhee et al. 2013) cause shifts in individual

50 behavior that contribute to ecological responses to environmental changes. In comparison, fewer

51 studies have investigated behavioral responses of terrestrial animals to changes in water availability,

52 especially in ectotherms (Pintor et al. 2016; Pirtle et al. 2019). The behavioral responses allowing

53 organisms to control water inputs and losses can be viewed as components of the hydroregulation

54 behavior (Pintor et al., 2016; Pirtle et al., 2019). Analogous to behavioral thermoregulation

55 (Angilletta, 2009), behavioral hydroregulation must be shaped by a balance between benefits (e.g.,

56 ability to reach an optimal hydration state) and costs (e.g., risks of predation or heat stress during

57 water foraging). As most scenarios of global changes predict a higher frequency of drought events

58 as well as average changes in precipitation regimes (Field et al. 2012), understanding drivers and

59 patterns of behavioral hydroregulation and its plasticity has become essential to unravel the

60 multifactorial consequences of global changes on terrestrial organisms (Albright et al., 2017;

61 Kearney \& Porter, 2009; Kearney et al. 2018; Pirtle et al., 2019).

62 Water is a critical resource and a limiting factor for terrestrial animals living in chronically warm

63 and dry environmental conditions such as xeric or semi-xeric environments (Davis \& DeNardo,

64 2009; Kearney et al., 2018; Long et al., 2014; Zylstra et al. 2013) as well as during droughts and

65 warm spells in mesic or tropical habitats (Anderson \& Andrade, 2017; Marquis et al. 2008). Thus,

66 terrestrial animals have evolved plastic behavioral responses to cope with spatio-temporal

67 fluctuations in water availability and maintain a homeostatic hydration state. One behavioral

68 strategy against water stress involves long-range movements and dispersal responses (i.e., 
69 behavioral flight response) to avoid desiccating environments (Massot et al. 2002; Rozen-Rechels et 70 al., 2018). An alternative behavioral strategy involves shifts in activity patterns (e.g., diel activity)

71 and microhabitat selection without change in home range location (i.e., behavioral fight response;

72 Lorenzon et al. 1999; Pintor et al. 2016). Such behavioral fight responses can improve water

73 balance by limiting water loss and/or by increasing metabolic or dietary water intake. For example,

74 some lizard species reduce their behavioral or locomotor activity during periods of water restriction

75 to reduce evaporative water loss (Davis \& DeNardo, 2010; Kearney et al., 2018; Lorenzon et al.,

76 1999; Pirtle et al., 2019) while other species shift their activity towards time periods with moister

77 conditions and a higher availability of free standing water (Davis \& DeNardo, 2010; Kearney et al.,

78 2018). Plasticity of microhabitat selection is also critical for some organisms to avoid water stress

79 and it may include selection of shadier basking or retreat sites during periods of activity and

80 differential use of moist and cold shelters during periods of inactivity (e.g., in snakes and lizards,

81 Guillon et al. 2013; Dupoué et al. 2015a; Pintor et al. 2016). So far, we still lack a comprehensive

82 quantification of the drivers and patterns that characterize behavioral hydroregulation in ectotherms,

83 especially dry-skinned vertebrate species, which were thought to be little affected by water

84 conditions until recently (Pintor et al., 2016; Rozen-Rechels et al., 2018). Nonetheless, it is

85 commonly accepted that individual performance of ectotherms are strongly influenced by hydration

86 state (e.g., Anderson and Andrade 2017), and recent mechanistic models highlight the critical role of

87 behavioral hydroregulation as a determinant of water balance across the distribution range of dry-

88 skinned lizard species (Pirtle et al., 2019).

89 The drivers and mechanisms of behavioral thermoregulation and hydroregulation are usually not

90 independent in wild animal populations because environmental changes in water availability usually

91 correlate with changes in thermal conditions on the one hand (e.g., drought and heat waves, Kelley

92 et al. 2015), and because of the coupling between the water and the heat budget of animals on the

93 other (e.g., Kearney and Porter 2009). This makes it hard to distinguish between both behaviors

94 (e.g., Davis and DeNardo 2009). In general, thermo-hydroregulation behavioral strategies must 
95 include the interactive set of behaviors that control both water balance and body temperature. In the

96 framework of thermo-hydroregulation, we predict a behavioral trade-off between water balance and

97 heat budget regulation because some thermoregulation behaviors, such as exposure to sunlight to

98 increase body temperature, also frequently enhance water loss rates in desiccating conditions (e.g.,

99 Dupoué et al. 2015a; Lourdais et al. 2017; Pirtle et al. 2019). Thus, water availability not only

100 influences hydroregulation but also thermoregulation, and water restriction can for example reduce

101 basking effort. Mechanisms of thermo-hydroregulation may also be more complex than the sum of

102 thermoregulation and hydroregulation behaviors, especially when desiccation risks occur jointly

103 with heat stress. Empirical studies aiming to disentangle the effects of water availability and

104 temperature, and their consequences for water balance and heat budget, are therefore crucial to fully

105 comprehend thermo-hydroregulation strategies and their mechanisms.

106 Thermoregulation strategies range from thermoconforming, when organisms conform to their

107 environmental temperature, to perfect thermoregulation when organism maintain a high

108 thermoregulation accuracy (constant body temperature at the preferred level) irrespective of the

109 thermal quality of the habitat (Angilletta, 2009). In a cost-free environment, thermal adaptation

110 models predict that ectotherms should be able to maintain a body temperature very close to their

111 preferred body temperature and that the preferred body temperature should optimize performances

112 and fitness (Angilletta, 2009; Herczeg et al. 2006; Huey \& Slatkin, 1976). In an environment with

113 desiccation risks due to suboptimal water inputs relative to standard water loss rates, ectotherms

114 should lower their thermal preferences in order to limit water losses and optimize performances that

115 are constrained by both hydration state and body temperature (Anderson \& Andrade, 2017;

116 Ladyman \& Bradshaw, 2003). This plastic response is called thermal depression and has been

117 observed in snakes exposed to seasonal or experimental dehydration (Ladyman \& Bradshaw, 2003).

118 However, the extent to which dehydration risks influence the accuracy of thermoregulation, defined

119 as the difference between preferred body temperature measured during unconstrained

120 thermoregulation (e.g., a neutral arena) and realized body temperature in a constrained environment 
121 (Angilletta, 2009; Blouin-Demers \& Nadeau, 2005; Hertz et al. 1993), is yet to be understood.

122 Dehydration risks may increase the cost of thermoregulation, and thermoregulation accuracy should 123 therefore decrease when low water availability or high water loss rates compromise water balance

124 (Blouin-Demers \& Nadeau, 2005; Huey \& Slatkin, 1976; Sears \& Angilletta, 2015). To our

125 knowledge, no study to date has tested how thermoregulation accuracy responds to dehydration 126 risks (Angilletta, 2009).

127 In this study, we used a laboratory experiment to quantify the behavioral responses to a chronic 128 water restriction and acute heat stress in the European common lizard Zootoca vivipara

129 (Lichtenstein, 1823). This cold-adapted species inhabits mesic environment and is tightly dependent 130 on humid conditions in the wild (Dupoué et al., 2017; Lorenzon et al., 1999; Massot et al., 2002). In 131 previous studies, we have shown that common lizards exposed to dry soil conditions invest more in 132 exploration behaviors (Rozen-Rechels et al., 2018), and juvenile lizards living in dry habitats 133 disperse more from their natal home range (Massot et al., 2002), whereas sub-adults reduce their 134 locomotor activity during a chronic water restriction (Lorenzon et al., 1999). Here, we repeatedly measured daily patterns of individual activity and microhabitat selection as well as body

136 temperature and thermoregulation accuracy during one week in adult individuals, gravid females 137 and males, exposed to a chronic water restriction (Dupoué et al., 2018) compared to individuals 138 having access to water ad libitum. To quantify potential interactions between water deprivation and 139 heat stress, we implemented a mid-day heat stress every two days. We also assessed thermal 140 preferences, body mass and hydration state (plasma osmolality) before and after the experiment. 141 Based on an earlier study of activity patterns in sub-adults (Lorenzon et al., 1999), we predicted 142 lower activity rates and/or shifts of activity towards cooler hours in water restricted animals, as well 143 as biases in microhabitat selection towards cooler and wetter shelters. We also expected a thermal 144 depression and a lower accuracy of thermoregulation if water-restriction enhances thermoregulation 145 costs. We predicted that behavioral effects of water deprivation would be amplified during 146 simulated heat stress. 


\section{Material and methods}

\section{Study species and sampling}

149 Common lizards of this study were captured in semi-natural captive populations in outdoor

150 enclosures located at CEREEP-Ecotron IleDeFrance research center in France $\left(48^{\circ} 17^{\prime} \mathrm{N}, 2^{\circ} 41^{\prime} \mathrm{E}\right)$.

151 These enclosures include a permanent and natural grassland vegetation and refuges/basking sites

152 made of rocks and logs. Individuals have a permanent access to free water through artificial ponds

153 which get filled with rain. Enclosures are delimited by plastic walls preventing escapes and ground

154 predation, and covered with nets to prevent avian predation. In 2018, one population was composed

155 of $71 \pm 9$ (standard deviation SD) individuals, mainly yearlings (50 \pm 7 individuals). Food was composed of local wild arthropods or annelids (spiders, worms, crickets) and in quantities that we suppose to be ad libitum as we did not observe differential survival rate of individuals compared to year of lower population densities. Mating season usually starts with emergence of females around

March-April and lasts around 2 to 4 weeks. Mating occurs between late March and early April, followed by ovulation and fertilization, and a gestation period that lasts two months on average. From May $3^{\text {rd }}, 2018$ to May $7^{\text {th }}, 2018$ we captured 72 adult individuals in 10 different $100-\mathrm{m}^{2}$ outdoor enclosures. At capture, lizards were measured for snout-vent length (SVL, with a rule, \pm 0.5 $\mathrm{mm}$ ) and body mass (BM, OHAUS, Adventurer, $220 \mathrm{~g}, \pm 1 \mathrm{mg}$ ), then placed in individual terraria

$164(18 \times 11 \times 12 \mathrm{~cm})$ with a shelter and sterilized peat soil as substratum. This sample was half composed of pregnant females (mean \pm SD; SVL: $64 \pm 3 \mathrm{~mm}$; BM: $5.25 \pm 0.79 \mathrm{~g}$ ) and of postreproductive males (SVL: $58 \pm 2 \mathrm{~mm}$; BM: $4.42 \pm 0.32 \mathrm{~g}$ ). Terraria were located in a temperaturecontrolled room $\left(23^{\circ} \mathrm{C}\right.$ from 09:00 to $18: 00,16^{\circ} \mathrm{C}$ at night). Individuals were fed three times a week with $300 \pm 10 \mathrm{mg}$ of live house crickets (Acheta domestica). In normal housing conditions, water was available ad-libitum in a petri dish and sprayed three times a day (09:00, 13:00 and 17:00). After a minimum acclimation period of one week, individuals were sorted in three trial groups (24

171 individuals per group) tested between May $10^{\text {th }}$ to May $20^{\text {st }}$ (trial 1$)$, May $21^{\text {st }}$ to May $31^{\text {st }}$ (trial 2 ) 172 or June $1^{\text {st }}$ to June $11^{\text {th }}$ (trial 3). Males were randomly attributed to each trial group. Females were 
173 sorted according to their SVL such that longer and older females, which usually give birth earlier

174 (Rutschmann et al., 2016), were tested first to avoid a strong variation in gestation stage among

175 trials (trial 1: $68 \pm 2 \mathrm{~mm}$; trial 2: $64 \pm 1 \mathrm{~mm}$; trial 3: $61 \pm 2 \mathrm{~mm}$ ). Inside each trial group, individuals

176 were randomly attributed to a control treatment or to the water-restricted treatment (Control

177 females: SVL: $64 \pm 3 \mathrm{~mm}$; BM: $5.10 \pm 0.84 \mathrm{~g}$; Water-restricted females: SVL: $65 \pm 3 \mathrm{~mm}, F_{1,34}=$

178 0.66, $p=0.42$; BM: $5.51 \pm 0.73 \mathrm{~g}, F_{1,34}=0.32, p=0.57$; Control males: SVL: $58 \pm 3 \mathrm{~mm}$; BM:

$1794.43 \pm 0.33 \mathrm{~g}$; Water-restricted males: SVL: $57 \pm 2 \mathrm{~mm}, F_{1,34}=2.11, p=0.16$; BM: $4.41 \pm 0.31 \mathrm{~g}$,

$\left.180 \quad F_{1,34}=0.08, p=0.78\right)$. To conform with Animal Welfare recommendations, we ensured all

181 individuals were healthy by checking body condition, behavior and parasite load before the

182 beginning and at the end of the experiment.

183 Experimental design

184 Experiments were performed in open-top arenas $(\mathrm{N}=12,78 \times 56 \times 44 \mathrm{~cm})$ installed in a

185 temperature-controlled room maintained at $20^{\circ} \mathrm{C}$ during day and night. In a $13^{\text {rd }}$ terrarium we

186 measured all micro-habitats thermal characteristics using operative temperature copper models

187 mimicking the lizards thermal properties in which were fixed HOBO ${ }^{\circledR}$ Pro v2 U23-003 (ONSET

188 Cape Cod, Massachusetts) temperature loggers (see Supplementary Information). Arenas were filled

189 with a substratum of dry and sterilized peat soil and equipped with one plastic shelter (Exo-Terra ${ }^{\circledR}$

190 cave, $7.6 \times 15.2 \times 5.1 \mathrm{~cm}$ ) at each corner. At one side of the arena, hereafter called the warm side,

191 two 40W light bulbs were placed above each shelter in order to warm the surface temperature at

192 approximately $35.9 \pm 4.2^{\circ} \mathrm{C}$ during daytime (between 8 am and $5 \mathrm{pm}$, similar to a standard early

193 summer activity day, see Supplementary Information and Figure S1), which corresponds to slightly

194 more than the preferred body temperature in common lizards (Gvoždík \& Castilla, 2001). The other

195 side of the terrarium, hereafter called the cold side, was maintained at approximately $24.5 \pm 2.0^{\circ} \mathrm{C}$

196 during daytime (between $8 \mathrm{am}$ and 5pm, see Figure S1), which is well below the preferred body

197 temperature range. At both sides, soil and air inside one shelter was made wet by adding a thin

198 sponge regularly moistened on top of the substrate, whereas the other shelter was kept dry by 
adding the same kind of sponge without wetting. Due to evaporative cooling effect, temperature in

200 wet shelters was colder than in dry shelters (warm side: $30.0 \pm 3.1^{\circ} \mathrm{C}$ in wet vs. $32.0 \pm 3.7^{\circ} \mathrm{C}$ in 201 dry, $F_{1,8841}=580.8, p<0.0001$; cold side: $22.8 \pm 1.8{ }^{\circ} \mathrm{C}$ in wet vs. $24.6 \pm 2.0^{\circ} \mathrm{C}$ in dry, $F_{1,6944}=$

202 2447.7, $p<0.0001$; see Figure S1). Yet, all temperature records on the cold side remained within

203 the thermal preference set of the species, while they remained in the set on the warm side. Wet

204 shelters had also higher water density (water vapor pressure calculated from relative humidity

205 measurements with iButton DS1923, Maxim Integrated, San Jose, California following Tieleman et 206 al. 2002 procedure) than dry ones (warm side: $23.6 \pm 2.1$ g.m $\mathrm{m}^{-3}$ in wet vs. $12.2 \pm 2.9$ g.m $\mathrm{m}^{-3}$ in dry, $207 F_{1,1598}=8108, p<0.0001$; cold side: $17.7 \pm 1.2$ g.m $\mathrm{m}^{-3}$ in wet vs. $11.6 \pm 1.7 \mathrm{~g} \cdot \mathrm{m}^{-3}$ in dry, $F_{1,1594}=$ $2086540, p<0.0001$; see Supplementary Information). We randomly assigned a wet or dry treatment to 209 the shelters on each side in each terrarium. In the center of the arena, we placed two large petri 210 dishes ( $\sim 8 \mathrm{~cm}$ of diameter, $0.5 \mathrm{~cm}$ deep) to store free-standing water. We placed above the middle of 211 the warm side an infrared halogen $50 \mathrm{~W}$ bulb to optionally change thermal conditions to $40-42^{\circ} \mathrm{C}$ 212 substrate and air temperature on the warm side, which is close to the critical thermal maximum for 213 this species (Gvoždík \& Castilla, 2001). At night, temperatures were of $20.0 \pm 1.1^{\circ} \mathrm{C}$. Two UVB $21430 \mathrm{~W}$ neon tubes (Reptisun 10.0, white light) provided white light above each arena during daytime.

215 We installed one male and one size-matched female in each arena during each trial. At this time of 216 year, males do not attempt to copulate with gravid, non-receptive adult females, and aggressive 217 interactions among lizards are rare (Fitze et al., 2005). Indeed, we did not observe any aggressive 218 behavior during this study. At day 0 , animals were put in the arenas until day 8 . Lights bulbs were 219 turned on automatically during daytime every day and infrared halogen bulbs were automatically 220 turned on from 11:00 to 14:00 at day 2, day 4, day 6 and day 8 to mimic a mid-day heat stress in the 221 warm side. During day 0, arenas were sprayed with water three times $(07: 30,14: 00,17: 00)$ to 222 provide mist and petri dishes were constantly filled with water (control treatment). Spraying lasted 223 approximately 5 seconds and was always made by the same observer in the same manner, and 224 aimed at having free water available as droplets that dried quickly. From day 1 to day 8 , half of the 
225 individuals were exposed to a sub-lethal water restriction during which mist was only provided in

226 early morning (08:00) and no free-standing water was available (droplets in empty petri dishes were

227 dried). Individuals were fed with $200 \pm 10 \mathrm{mg}$ of live house crickets (Acheta domestica) every day

228 at 10:00. The chronology of the experiment for one experimental group is summarized in Figure S3.

\section{Pre-manipulation and post-manipulation measurements}

230 In the morning of the day before day 0 and after day 8 , we measured thermal preferences of all

231 individuals in a neutral thermal gradient $(80 \times 15 \times 20 \mathrm{~cm})$ filled with a substratum of dried peat

232 soil. We placed a plate of wood on the ground and installed a $40 \mathrm{~W}$ heat bulb $15 \mathrm{~cm}$ above the

233 ground at the warm side of the gradient $\left(50 \pm 5.9^{\circ} \mathrm{C}\right.$ surface temperature $)$. The cold side of the

234 gradient was maintained at a low temperature $\left(24.3 \pm 2.0^{\circ} \mathrm{C}\right)$. A UVB $30 \mathrm{~W}$ neon tube provided

235 natural, white light conditions above each thermal gradient. Heat bulbs were turned on at 08:00 for

236 one hour before individuals were placed in each thermal gradient for habituation during 30 minutes.

237 At 09:30 and every 20 minutes until 13:10, surface temperature $\mathrm{T}_{\mathrm{p}}$ of all lizards was measured using

238 an infrared thermometer (Raytek, Raynger MX2). This measure, strongly correlated with internal

239 body temperature data, provides an estimate of preferred body temperature (Artacho et al., 2013).

240 We then calculated the difference between each record at the end of the experiment and the record

241 made on the same individual at the same time of the day before the experiment, hereafter called

$242 \Delta \mathrm{T}_{\mathrm{p}}$.

243 After thermal preferences measurements, individuals were weighted to calculate body mass change

244 between the beginning and the end of the experiment $(\triangle \mathrm{BM})$ and relocated in their home terrarium

245 for an hour or two until approximately 15:00. We then sampled $10 \mu \mathrm{L}$ of blood from the post-orbital

246 sinus using a standard protocol (Meylan et al., 2003) to assess changes in plasma osmolality. Blood

247 samples were centrifuged at $11,000 \mathrm{~g}$ to separate plasma, which was kept frozen at approximately -

$24825^{\circ} \mathrm{C}$. Plasma osmolality was determined from two aliquots of plasma diluted in physiological

249 serum using a vapor pressure osmometer (Wescor Vapro® 5520) following (Dupoué et al. 2018).

250 The osmolality was calculated as the average osmolality of the two aliquots corrected by the 
dilution minus the osmolality of a reference, physiological serum $\left(307 \pm 3 \mathrm{mOsm} \cdot \mathrm{kg}^{-1}\right) . \mathrm{We}$

252 assessed $\triangle \mathrm{OSMO}$ by subtracting final osmolality to initial osmolality.

\section{Behavioral data}

254 From day 0 to day 8 , we observed the behavior of lizards with a focal sampling every 30 minutes

255 from 08:00 to 17:00. At each sampling time, we observed whether the individual was "active" (i.e.

256 outside the shelter) or not (i.e. in the shelter or buried in the soil). When active, we recorded when

257 the individual was basking (not moving under the heat spot), moving, eating, drinking, or immobile

258 but not basking. When the individual was active, we measured the surface body temperature of its

259 dorsum using an infrared thermometer as detailed above. When the individual was not visible, we

260 searched under its shelter by having a quick look, and, when the lizard was still not found, we

261 assumed that it was buried into the soil and did not disturb it. We made a total of 12,312 focal

262 observations of the 72 lizards and 3,334 temperature recordings during the 3 trials and 9 days of

263 each trial.

\section{Statistical analyses}

265 Statistical analyses were performed using R version 3.4.4 "Someone to Lean On" (R Core Team,

266 2018). In all cases, the best models were inferred with backward model selection based on log-

267 likelihood ratio tests. We evaluated significance by comparing the best-fit model with a reduced

268 model, from which was subtracted the effect of interest using log-lokelihood ratios. We also

269 provided the estimated effect \pm standard error.

270 Differences in $\triangle \mathrm{BM}$ and $\triangle \mathrm{OSMO}$ were assessed with ANCOVAs using linear models with the two-

271 way interaction between treatment and sex as well as the additive effects of the trial group as fixed

272 effects. In the case of $\Delta \mathrm{BM}$, we also added the initial mass as a fixed effect as mass change should

273 be relative to the size of the animal.

274 We tested the variations of the behaviors and thermoregulation statistics of interest using

275 ANCOVAs fitted with linear mixed models with the lme function from the nlme package (Pinheiro

$276 \&$ Bates, 2006) and generalized linear mixed models with the glmer function from the $l m e 4$ package 
277 (Bates et al., 2015). In order to analyze the effect of water restriction on thermal preference, we first

278 compared $\Delta \mathrm{T}_{\mathrm{p}}$ at each time of day between control and water-restricted individuals using a linear

279 mixed-effect model with the three-way interaction between time of day, treatment and sex as fixed

280 effects. To calculate contrasts, we set the intercept of the model to the last observation of the day

281 (i.e. time of day $=13: 10$ ). We assessed inter-group variation by considering the experimental group

282 as a fixed effect and we took inter-individual variability into account by defining an individual level

283 random effect.

284 Based on our thermal preference data and body temperature, we inferred thermoregulation

285 inaccuracy at each record by calculating the absolute difference between body temperature record

286 and thermal preference (Hertz et al., 1993; Sears et al., 2016). To infer thermal preference

287 corresponding to the same day as the one of each record, we assumed a linear change (increase or

288 decrease depending on each individual) of preferred body temperature (measured in the thermal

289 gradient) from before to after the experiment. Then, to analyze the effect of water restriction on

290 body temperature and thermoregulation inaccuracy, we ran linear mixed-model regressions

291 including as fixed effects the three-way interaction between sex, treatment and the number of days

292 since the beginning of the experiment (hereafter referred to as $D_{\exp }$ ) as well as the trial group as an

293 additive effect. To account for potential differences among arenas (Figure S2) and individuals, we

294 used lizard identity nested in the corresponding arena as random effects in the following models ran

295 on behavioral data.

296 We focused our analyses of behavioral data on emergence time (i.e. time of first activity each day),

297 behavioral budget and shelter choice. First, we tested the effect of water restriction on emergence

298 time using the Cox survival model from the package coxme (Therneau, 2018). The survival model

299 analyses the expected time spent before an event happened. Each lizard has a constant per-unit-time

300 probability to emerge (death event) until the end of the day during which we consider that it never

301 went out ("survived"; $7.8 \%$ of our observations). The model estimates the mean time of emergence. 
302 We implemented in this model a three-way interaction of $D_{\exp }$, treatment and sex as fixed effect as

303 well as the trial group as an additive effect.

304 We then tested the influence of water restriction on four behavioral items: i.e., proportion of time

305 spent active, proportion of time spent basking, proportion of time spent in hot vs. cold shelters, and

306 proportion of time spent in wet hot shelters vs. dry hot shelters. We did not analyze the proportion

307 of time spent in wet cold shelters vs. dry cold shelters as individuals spent between $80 \%$ to $95 \%$ of

308 their time in the warm side. For each behavioral item, we counted the number of occurrences per

309 day and analyzed proportions using generalized linear mixed models with binomial errors,

310 comparing (i) the number of times an individual was active to the number of observations in the day

311 (19), (ii) the number of times it was basking to the number of time it was active, (iii) the number of

312 time it selected a hot shelter to the number of time it selected a cold shelter, and (iv) the number of

313 time it selected a wet hot shelter to the number of time it selected a dry hot shelter. We included the

314 three-way interaction of $D_{\text {exp }}$, treatment and sex as fixed effects as well as the trial group as an

315 additive effect. We restricted this analysis to days without heat stress (D0, D1, D3, D5, D7).

316 Analyses of shelter selection showed over-dispersion of data that we corrected by using an

317 observation-level random effect (Harrison, 2014).

318 In order to analyze the effect of heat stress and water restriction, we calculated the behavioral

319 budget of lizards from 11:30 to 14:00, which corresponds to the time of day when heat stress was

320 simulated. We analyzed the interaction between heat stress and water restriction considering all

321 days from D0 to D8. We tested the three-way interaction of heat stress and water restriction with

322 sex and $D_{\text {exp }}$, as well as the trial group as an additive effect. Since the distribution of the shelter

323 selection traits (warm vs. cold shelter selection and wet vs. dry warm shelter selection) was close to

324 bimodal, we did not analyze the proportion of shelter use but instead compared a bimodal variable

325 in each case (i.e., lizard in the warm shelter all the time vs. other cases, lizard in the wet warm

326 shelter all the time vs. other cases).

\section{Results}


329 Body mass change was smaller in water restricted lizards than in controls $\left(F_{1,66}=9.50, p=0.003\right)$

330 independently from sex (water treatment $\times \operatorname{sex}: F_{1,65}=2.74, p=0.1$ ). Males had a lower $\Delta \mathrm{BM}$ than

331 females $\left(-0.37 \pm 0.08 \mathrm{~g} ; F_{1,66}=19.7, p<0.0001\right)$. Thus, we recorded a gain of mass in control

332 females $(0.4 \pm 0.1 \mathrm{~g})$, no change in $\mathrm{BM}$ in water-restricted females $(0.1 \pm 0.1 \mathrm{~g})$ and control males

$333(0 \pm 0.1 \mathrm{~g})$, and a mass loss in water-restricted males $(-0.3 \pm 0.1 \mathrm{~g}$; Table 1$)$. In addition, water-

334 restricted individuals had a higher osmolality change (i.e., higher plasma dehydration) than control

335 individuals (water treatment: $F_{1,67}=4.59, p=0.04$ ) independently from sex (water treatment $\times$ sex:

$336 F_{1,65}=0.01, p=0.91$; sex: $F_{1,65}=0.05, p=0.94$, see Table 1$)$.

337 Change in thermal preferences and thermoregulation accuracy

338 The preferred body temperatures were most of the time lower after the experiment than before with 339 an average $\Delta \mathrm{T}_{\mathrm{p}}=-1.70 \pm 0.20{ }^{\circ} \mathrm{C}$, and only nine individuals out of 72 had positive $\Delta \mathrm{T}_{\mathrm{p}}$ records

340 (Table 1, Figure 1A). $\Delta \mathrm{T}_{\mathrm{p}}$ was significantly higher in males than in females (sex: $F_{1,69}=12.75, p=$

341 0.0007). Control individuals had a constant $\Delta \mathrm{T}_{\mathrm{p}}$ across times of day, while water-restricted

342 individuals $\Delta \mathrm{T}_{\mathrm{p}}$ dropped approximately by $0.12 \pm 0.05^{\circ} \mathrm{C}$ every 20 minutes with time of day (time 343 of the day: $F_{1,779}=2.83, p=0.09$; time of the day $\times$ water treatment: $\left.F_{1,779}=6.63, p=0.01\right)$. At

344 midday (13:10, end of our test), water-restricted lizards had a $\Delta \mathrm{T}_{\mathrm{p}}$ lower of $1.30 \pm 0.45^{\circ} \mathrm{C}$ than

345 controls irrespective of sex (Figure 1A; water treatment: $F_{1,69}=8.36, p=0.005$; water treatment $\times$ 346 sex: $\left.F_{1,69}=0.64, p=0.43\right)$.

347 Surface body temperature records during the experiment were influenced significantly by a

348 three-way interaction of $D_{\exp }$, water treatment and $\operatorname{sex}\left(D_{\exp } \times\right.$ water treatment $\times \operatorname{sex}: F_{1,3258}=4.61$, $349 p=0.03$; Figure 1B). The body temperature of control females decreased by $0.19 \pm 0.05^{\circ} \mathrm{C}$ day $^{-1}$ 350 during the experiment, but it decreased twice as fast in water-restricted females (contrast $=0.24 \pm$ $3510.07{ }^{\circ} \mathrm{C}$. day $^{-1} ; t_{3258}=-3.37, p=0.0008$ ). No such effect was found in males (Figure 1B) but the 352 body temperature was higher of $2.13 \pm 0.41{ }^{\circ} \mathrm{C}$ in males than in females $\left(t_{66}=5.15, p<0.0001\right)$. 
interaction with $D_{\exp }\left(D_{\exp } \times\right.$ water treatment: $F_{1,3260}=5.17, p=0.02$; Figure 1C). Thermoregulation inaccuracy of control individuals did not change through time $\left(t_{3260}=0.55, p=0.58\right)$. On the contrary, thermoregulation became less accurate with $D_{\exp }$ in water-restricted individuals (contrast: $<0.01, p=1)$. On average, males were slightly less accurate in their thermoregulation than females $\left(0.3 \pm 0.1^{\circ} \mathrm{C}\right.$, sex: $F_{1,69}=4.25, p=0.04 ;$ sex $\times$ water treatment: $\left.F_{1,68}=0.34, p=0.56\right)$.

\section{Behavioral flexibility}

361 On average, an individual was seen active $5.2 \pm 0.1$ times a day and emerged for the first time of the day between 9:30 and 10:00, with ca. 50\% of individuals active by 08:30 (see Figure 2). Lizards were seen in a shelter $66 \pm 1 \%$ of the day and selected a warm refuge $88 \pm 1 \%$ of the time, which was also wet $69 \pm 1 \%$ of the time. When active, a lizard was basking on average $79 \pm 1 \%$ of the time. Emergence time was influenced significantly by the three-way interaction between water treatment, $D_{\exp }$ and sex $\left(\chi^{2}=18.23, \mathrm{df}=1, p<0.0001\right.$; Figure 2). Control females emerged later during daytime $(z=-3.92, p<0.0001)$. On the contrary, water-restricted females emerged significantly earlier than control ones with $D_{\exp }$ (contrast: $0.26 \pm 0.05$ day $^{-1} ; z=3.59, p=0.0003$ ) as well as control males $(z=3.23, p=0.001)$ and water-restricted males $(z=2.50, p=0.01)$.

Activity rate was also influenced by a three-way interaction between sex, water treatment and $D_{\exp }\left(\chi^{2}=3.96, \mathrm{df}=1, \mathrm{p}=0.046\right.$, Figure $\left.3 \mathrm{~A}\right)$. Females reduced their activity across time of the experiment $(z=-2.40, p=0.02)$ irrespective of water treatment $(z=0.19, p=0.85)$. On the contrary, control males did not change their activity rate while water-restricted males reduced it (Figure 3A).

374 Lizards also reduced their basking effort during the experiment $\left(\chi^{2}=12.8, \mathrm{df}=1, p=0.003\right.$; Figure

$3753 \mathrm{~B})$ and males basked more than females $\left(\chi^{2}=4.45 \mathrm{df}=1, p=0.03\right)$. Water treatments did not influence basking effort (water treatment: $\chi^{2}=3.25, \mathrm{df}=1, \mathrm{p}=0.07$; water treatment $\times D_{\text {exp }}: \chi^{2}=$ $0.01, \mathrm{df}=1, p=0.92$; water treatment $\times \operatorname{sex}: \chi^{2}=0.12, \mathrm{df}=1, p=0.72$ ). These results on 
towards the earliest hours of the day (08:00: 20\% active at D0 vs. $\sim 50 \%$ active at D7; 10:00: $\sim 50 \%$

380 active at D0 vs. $\sim 25 \%$ active at D7, see Figure 3 ).

Warm vs. cold shelter selection was significantly influenced by the two-way interactions of

382 water treatment with $D_{\exp }\left(\chi^{2}=6.47, \mathrm{df}=1, p=0.01\right)$ and with $\operatorname{sex}\left(\chi^{2}=4.26, \mathrm{df}=1, p=0.04\right)$.

383 Control individuals tend to shift towards warmer shelters across the experiment $(z=1.94, p=$

3840.053 ) while water-restricted individuals shifted progressively to cooler shelters (contrast: $-0.23 \pm$

3850.09 day $\left.^{-1} ; z=-2.55, p=0.01\right)$. In addition, at day 0 , there was no difference in shelter selection

386 between water-restricted females and control individuals $(z=0.38, p=0.23)$, however, control

387 males selected colder shelters than water-restricted males (Figure 3C). Regarding wet shelter

388 selection in the warm side of the terrarium, we found that water-restricted individuals selected the

389 wetter and cooler shelter on average (contrast: $1.43 \pm 0.39$; water treatment: $\chi^{2}=12.4, \mathrm{df}=1, p=$

3900.0004 ; water treatment $\times D_{\text {exp }}: \chi^{2}=2.41, \mathrm{df}=1, p=0.12$; water treatment $\times$ sex: $\chi^{2}=1.41, \mathrm{df}=2$,

$391 p=0.49$; Figure 3D). Irrespective of water treatment, individuals also shifted on average their

392 shelter selection towards the wetter shelter as the time of the experiment proceeded $\left(\chi^{2}=7.22, \mathrm{df}=\right.$

$3931, p=0.007$, Figure 3D).

394 Effects of simulated heat stress on behavior

395 In this section, we focus on patterns and effects of water-restriction that are different from those

396 described during days without heat stress in the previous section, but Table S1 summarizes all best

397 models for heat stress simulation. Between 11:00 and 14:00, heat stress significantly reduced

398 behavioral activity and basking effort (Figure 4A and 4B), but this reduction was independent from

399 the water restriction treatment (activity: $\chi^{2}=2.72, \mathrm{df}=1, p=0.10$; basking: $\chi^{2}=0.63, \mathrm{df}=1, p=$

400 0.73). Heat stress simulation also reduced the selection of warm shelters in females $(z=-3.30, p=$

4010.001 ) but not in males (post-hoc test: $z=-1.5, p=0.13$ ), independently from the water restriction

402 treatment (Figure 4C). During simulated heat stress, individuals more often selected the wet and

403 cool shelter (contrast: $0.56 \pm 0.19 ; z=8.86, p=0.003$; Figure 4D), but this was again independent

404 from the water restriction treatment $\left(\chi^{2}=1.15, \mathrm{df}=1, p=0.28\right)$. Last, there was a tendency for 
water-restricted individuals to select the wet and cool shelters more often than control individuals with $D_{\exp }$ (Figure 4D), but this trend was not significant $\left(\chi^{2}=3.22, \mathrm{df}=1, p=0.07\right)$.

\section{Discussion}

408 Our experiment quantified changes in behavior and thermoregulation accuracy in response to a

409 chronic water restriction in a terrestrial ectotherm. As expected, water-restricted lizards displayed a

410 significantly higher osmolality than control individuals indicating that water restriction induced

411 physiological dehydration. This is corroborated by water-restricted females constant weight

412 contrary to control ones, and water-restricted males losing body mass relative to controls,

413 consistently with similar measurements in previous ecophysiological studies of water restriction in

414 common lizards (Dupoué et al., 2018). At the same time, water-restricted gravid females shifted

415 slightly their thermal preferences (measured in a neutral arena) towards lower temperatures than

416 control females (by ca. $1^{\circ} \mathrm{C}$ ) and also had lower body temperatures in water-restricted conditions

417 (by ca. $2^{\circ} \mathrm{C}$ ). Interestingly, in both males and females, water restriction decreased thermoregulation

418 accuracy with time more than controls. Our results also revealed that water-restricted females

419 shifted their activity to the early morning hours, whereas water-restricted males reduced their

420 average activity. Water-restricted individuals also shifted microhabitat selection to cooler and wetter

421 shelters. In addition, simulated heat stress strongly reduced activity and basking rate, and enhanced

422 microhabitat preference for cooler and wetter shelters but, unexpectedly, this effect did not depend

423 on water restriction treatment.

424 Overall, our observations are consistent with the prediction that common lizards unable to disperse

425 adopt behavioral fight strategies to conserve more water and mitigate the consequences of the

426 simulated mild but chronic water restriction on water balance (Lorenzon et al., 1999; Pirtle et al.,

427 2019). The behavioral fight syndrome included a diminution of locomotor and behavioral activity, a

428 change in daily activity patterns and some shifts of shelter selection strategies. The dominant

429 behavioral response to water restriction in females was a shift of their behavioral activity towards

430 the first hours of the day (Figure 2), a time period of the day that is cooler and wetter on average 
431 and when free standing water is available in the form of dew in both treatments (Figure S1). The

432 earlier activity of water-restricted females could thus be a strategy to forage for water and perform

433 standard activities in conditions in which desiccation risk is minimized. This result is consistent

434 with with those of empirical studies and quantitative models suggesting that changes in water

435 availability can be a dominant driver of seasonal or spatial changes in daily activity patterns in

436 squamate reptiles, and more generally in terrestrial ectotherms (Davis \& DeNardo, 2010; Kearney

437 et al., 2018; Wells, 2010).

438 In our experimental set-up, shelters in the warm side of the terrarium were at an operative

439 temperature of approximately $30-32^{\circ} \mathrm{C}$, which is close to females' but slightly below males'

440 preferred body temperature (Table 1). These shelters thus allow individuals to regulate body

441 temperature without effort and under low overheating risks, which is critical to perform optimally

442 some slow and temperature-dependent activities such as digestion (Stevenson, 1985). Cold side

443 shelters were, however, suboptimal for thermoregulation with temperatures ranging around 23-

$44425^{\circ} \mathrm{C}$. This explains the high rate of warm shelter use $(>75 \%)$ in our study. Wet shelters were also

445 three times less desiccating (vapor pressure deficit: 0.98 mbar in warm wet shelters, $0.36 \mathrm{mbar}$ in

446 cold ones) than dry ones (3.04 mbar in warm dry shelters, 1.5 mbar in cold ones) and differed on

447 average only by $2^{\circ} \mathrm{C}$ temperature difference due to evaporative cooling. We therefore suggest that

448 the differential use of wet over dry shelters is much more likely driven by hydroregulation than

449 thermoregulation behavior. Thus, water restricted individuals shifted their hydroregulation behavior

450 by increasing the use of wetter shelters, which is consistent with a strategy aiming at reducing

451 dehydration rate. At the same time, they used more often cool shelters, which are suboptimal for

452 thermoregulation but, on average, half less desiccating than warm ones. This shift suggests that

453 conditions of water restriction can trigger hydroregulation strategies critical for the maintenance of

454 water balance at the expanse of thermoregulation strategies, as suggested by Pintor et al. (2016). In

455 natural conditions, we suspect that ecological responses to drought and water restriction will

456 critically depend on the presence and distribution of cold and wet shelters or vegetation in the 
457 lizards' habitat (Pirtle et al., 2019). The distribution of such patches in the landscape in

458 complementation to other resources will be a predictor of the ability of organisms to cope with

459 changing moisture conditions through habitat selection (Sears \& Angilletta, 2015; Sears et al.,

460 2016).

461 Interestingly behavioral adjustments were not efficient enough to counter physiological dehydration

462 since lizards in this study suffered from a slight increase in plasma osmolality and decrease in body

463 mass change as in earlier laboratory experiments (Dupoué et al., 2018). The range of measured

464 changes in plasma osmolality in this study indicates a mild physiological dehydration (Dupoué et

465 al., 2018), and plasma osmolality levels of water-restricted individuals were also high compared to

466 baseline levels recorded in a range of natural populations with contrasted access to water (Dupoué

467 et al., 2017). In addition, we found gradual changes in behavioral responses of lizards in this

468 experiment, which suggests that they are mostly driven by changes in water balance instead of

469 water availability per se. Indeed, if lizards responded to water availability per se, behavioral

470 responses would be immediate while hydration state would likely change gradually during the

471 course of the experiment (Davis \& DeNardo, 2009; Dupoué et al., 2015a). We conclude that water

472 balance status is a cue to individual behavior changes, thus implying that behavioral fight traits are

473 condition-dependent behaviors (Buchanan, 2000).

474 Unexpectedly, we did not observe any interactive effect of water restriction and heat stress on

475 behavior. This could be explained by a lack of statistical power, as heat stress was too strong in our

476 set-up, or because hydration status does not influence sensitivity to heat stress in common lizards

477 (see Figure S1C). Behavioral responses to a simulated midday heat stress were consistent with

478 overheating avoidance, probably to avoid the risk of reaching maximum critical thermal limits and

479 to reduce evaporative water loss through skin and respiration. During the simulated heat stress,

480 lizards hide more often and seek more often cooler microhabitats which offered more optimal

481 thermal conditions (close to thermal preferences) than the warm side (see Figure S1C), a result

482 predicted by theoretical models of thermoregulation (Angilletta, 2009; Porter et al., 1973). They 
483 also selected wet shelters more often, independently from their hydration status, thus suggesting

484 that heat stress induced water-conservation behaviors. However, because wet shelters were also

485 significantly cooler during the heat stress, it is difficult to tell if this behavioral shift was a sign of

486 behavioral hydroregulation or thermoregulation. We were surprised by the absence of interaction

487 between the water balance status and the sensitivity to heat stress. Our study however suggests that

488 heat stress not only influences thermoregulation behaviors, but also water-related habitat selection

489 patterns.

490 Some behavioral effects of water restriction were different between sexes which might also simply

491 be the consequence of being gravid (all females expect one finally laid). Only females showed

492 strong differences in activity patterns in response to water restriction but both sexes adjusted their

493 microhabitats selection behaviors the same way. In both treatments, gravid females had lower

494 thermal preferences and lower active body temperatures. This average shift is consistent with

495 previous observations of thermal depression during gestation in the common lizard, suggesting that

496 thermal conditions for embryonic development are optimized around $29-30^{\circ} \mathrm{C}$ at the end of

497 gestation (Gvoždík \& Castilla, 2001; Le Galliard et al., 2003). We found minor changes in thermal

498 preferences in males only but the effects of water restriction on thermal preferences were similar in

499 both sexes. In sharp contrast, the active body temperature of males was not influenced by water

500 restriction and remained relatively high during the experiment. Altogether, these results support the

501 hypothesis that thermoregulation behaviors are more sensitive to water restriction in females than in

502 males, most likely because higher water needs during pregnancy select for stronger water-

503 conservation strategies in pregnant females than in non-reproductive individuals (Dupoué et al.,

504 2015b; Dupoué et al., 2018). In viviparous ectotherms, pregnancy leads to an increased demand for

505 water (Dupoué et al., 2016, 2018; Dupoué et al., 2015b), and pregnant females could alter their own

506 water balance to protect their embryos from hydric stress (Dupoué et al., 2016, 2018). In addition,

507 the trade-off between thermoregulation and hydroregulation is likely higher in pregnant females

508 because pregnancy induces morphological and physiological changes that increase standard water 
509 loss rates (Lorioux et al., 2013). As females and males faced similar physiological dehydration, we

510 speculate that plasticity of thermoregulation behaviors is critical for females to override the water

511 conflict with their embryos and maintain a constant survival and reproductive effort despite their

512 stronger reliance on water (as seen in Dupoué et al., 2018). We can not however conclude if these

513 differences are sex-specific, the consequence of being gravid or both of them.

514 We can not also exclude that competition between individuals in the same terrarium would have

515 affected our results. We did not observe any aggressive behavior among individuals, but we did not

516 continuously assess the behavior of individuals nor we can conclude at the absence of avoidance

517 behaviors. Competition for thermal resources is a well-known process (Downes and Shine 1998;

518 Angilletta 2009) and we might thus suppose that such competition might also occur for

519 microhabitats according to their moisture. The absence of sex-difference in thermoregulation

520 accuracy, which is expected to change with competition pressure, makes us think that competition

521 between females and males could be neglected. We also measured that water-restricted individuals

522 seemed to spend more time together than separated in shelters, especially in the wet and hot

523 shelters, while control individuals spent as much time together than separated (see Supplementary

524 Information). This is contradictory with the hypothesis that females and males are in competition

525 for microhabitats in our set-up; to properly conclude, this study should have been pursued with

526 more treatments on social conditions in the terrarium (e.g., solitary individuals or same sex

527 individuals).

528 Our study is the first experimental test of the effect of dehydration risk on thermoregulation

529 accuracy and it confirms the prediction of less accurate thermoregulation in water-restricted

530 environments. Since thermal conditions were constant across days and between treatments (see

531 Figure S1), we thus demonstrated unambiguously that the non-energetic costs of thermoregulation

532 due to risk of desiccation can impair thermoregulation efficiency, even in a simple laboratory set-up

533 in which thermoregulation is presumably less costly on average than in natural conditions

534 (Angilletta, 2009; Huey \& Slatkin, 1976; Sears \& Angilletta, 2015). The effects of water restriction 
on thermoregulation accuracy highlight potential behavioral conflicts between thermoregulation and

536 hydroregulation and suggest that water conservation might be prioritized over thermoregulation and

537 optimization of the energy budget in ectotherms (Basson et al., 2017; Herczeg et al., 2003). Our

538 study thus emphasizes that costs of hydroregulation on thermoregulation are critical in

539 understanding the responses of ectotherms to environmental changes.

\section{Acknowledgments}

541 Moved to title page for double-blind peer review purposes.

542 All applicable international, national, and/or institutional guidelines for the care and use of animals

543 were followed. Animal care and behavioral protocols were performed with permit APAFIS\#5109-

5442018040118468655 . Animal care and breeding was performed by authorized personnel under

545 permit agreement DTTP-2008-449 issued to XXX. Experiments were conducted under agreement

546 A7743117-341-1 delivered by the Préfecture de Seine-et-Marne. Animals were captured and

547 manipulated under authorization 2007-198-005 delivered by the Préfecture de Seine-et-Marne.

\section{Data Accessibility}

549 Analyses reported in this article can be reproduced using the data provided at publication on Dryad 550 (provided after acceptance).

\section{References}

552 Albright, T.P., Mutiibwa, D., Gerson, A.R., Smith, E.K., Talbot, W.A., O’Neill, J.J.,...Wolf, B.O.

553 (2017). Mapping evaporative water loss in desert passerines reveals an expanding threat of lethal

554 dehydration. Proceedings of the National Academy of Sciences, 114(9), 2283-2288.

555 Anderson, R.C.O., \& Andrade, D.V. (2017). Trading heat and hops for water: Dehydration effects

556 on locomotor performance, thermal limits, and thermoregulatory behavior of a terrestrial toad.

557 Ecology and Evolution, 7(21), 9066-9075.

558 Angilletta, M.J. (2009). Thermal adaptation: a theoretical and empirical synthesis. Oxford 559 University Press. 
560 Artacho, P., Jouanneau, I., \& Le Galliard, J.-F. (2013). Interindividual variation in thermal

561 sensitivity of maximal sprint speed, thermal behavior, and resting metabolic rate in a lizard.

562 Physiological and Biochemical Zoology, 86(4), 458-469.

563 Basson, C.H., Levy, O., Angilletta, M.J., \& Clusella-Trullas, S. (2017). Lizards paid a greater

564 opportunity cost to thermoregulate in a less heterogeneous environment. Functional Ecology, 31(4), $565856-865$.

566 Bates, D., Mächler, M., Bolker, B., \& Walker, S. (2015). Fitting Linear Mixed-Effects Models using 567 lme4. Journal of Statistical Software, 67(1), 1-48.

568 Beever, E.A., Hall, L.E., Varner, J., Loosen, A.E., Dunham, J.B., Gahl, M.K.,...Lawler, J.J. (2017).

569 Behavioral flexibility as a mechanism for coping with climate change. Frontiers in Ecology and the 570 Environment, 15(6), 299-308.

571 Blouin-Demers, G., \& Nadeau, P. (2005). The cost-benefit model of thermoregulation does not 572 predict lizard thermoregulatory behavior. Ecology, 86(3), 560-566. doi: 10.1890/04-1403

573 Buchanan, K. L. (2000). Stress and the evolution of condition-dependent signals. Trends in Ecology $574 \&$ Evolution, 15(4), 156-160.

575 Davis, J.R., \& DeNardo, D.F. (2009). Water supplementation affects the behavioral and 576 physiological ecology of Gila monsters (Heloderma suspectum) in the Sonoran Desert.

577 Physiological and Biochemical Zoology, 82(6), 739-748.

578 Davis, J.R., \& DeNardo, D.F. (2010). Seasonal Patterns of Body Condition, Hydration State, and 579 Activity of Gila Monsters (Heloderma suspectum) at a Sonoran Desert Site. Journal of 580 Herpetology, 44(1), 83-93.

581 Dupoué, A., Angelier, F., Brischoux, F., DeNardo, D.F., Trouvé, C., Parenteau, C., \& Lourdais, O. 582 (2016). Water deprivation increases maternal corticosterone levels and enhances offspring growth in 583 the snake Vipera aspis. Journal of Experimental Biology, 219(5), 658-667. 
584 Dupoué, A., Brischoux, F., Angelier, F., DeNardo, D. F., Wright, C.D., \& Lourdais, O. (2015b).

585 Intergenerational trade-off for water may induce a mother-offspring conflict in favour of embryos

586 in a viviparous snake. Functional Ecology, 29(3), 414-422.

587 Dupoué, A., Le Galliard, J.-F., Josserand, R., DeNardo, D.F., Decencière, B., Agostini, S., ...

588 Meylan, S. (2018). Water restriction causes an intergenerational trade- off and delayed mother589 offspring conflict in a viviparous lizard. Functional Ecology, 32(3), 676-686.

590 Dupoué, A., Rutschmann, A., Le Galliard, J.F., Miles, D. B., Clobert, J., DeNardo, D.F., ... Meylan, 591 S. (2017). Water availability and environmental temperature correlate with geographic variation in 592 water balance in common lizards. Oecologia, 185(4), 561-571.

593 Dupoué, A., Stahlschmidt, Z.R., Michaud, B., \& Lourdais, O. (2015a). Physiological state

594 influences evaporative water loss and microclimate preference in the snake Vipera aspis.

595 Physiology \& Behavior, 144, 82-89.

596 Field, C.B., Barros, V., Stocker, T.F., \& Dahe, Q. (2012). Managing the risks of extreme events and 597 disasters to advance climate change adaptation: special report of the intergovernmental panel on 598 climate change. Cambridge University Press.

599 Fitze, P. S., Le Galliard, J.-F., Federici, P., Richard, M., \& Clobert, J. (2005). Conflict over multiple600 partner mating between males and females of the polygynandrous Common lizards. Evolution, $60159(11), 2451-2459$.

602 Guillon, M., Guiller, G., DeNardo, D.F., \& Lourdais, O. (2013). Microclimate preferences correlate 603 with contrasted evaporative water loss in parapatric vipers at their contact zone. Canadian Journal 604 of Zoology, 92(1), 81-86.

605 Gvoždík, L., \& Castilla, A.M. (2001). A comparative study of preferred body temperatures and 606 critical thermal tolerance limits among populations of Zootoca vivipara (Squamata: Lacertidae) 607 along an altitudinal gradient. Journal of Herpetology, 35(3), 486-492.

608 Harrison, X.A. (2014). Using observation-level random effects to model overdispersion in count 609 data in ecology and evolution. PeerJ, 2, e616. 
610 Herczeg, G., Gonda, A., Saarikivi, J., \& Merilä, J. (2006). Experimental support for the cost-benefit

611 model of lizard thermoregulation. Behavioral Ecology and Sociobiology, 60(3), 405-414.

612 Herczeg, G., Kovács, T., Hettyey, A., \& Merilä, J. (2003). To thermoconform or thermoregulate? An

613 assessment of thermoregulation opportunities for the lizard Zootoca vivipara in the subarctic. Polar

614 Biology, 26(7), 486-490.

615 Hertz, P.E., Huey, R.B., \& Stevenson, R.D. (1993). Evaluating temperature regulation by field-

616 active ectotherms: the fallacy of the inappropriate question. American Naturalist, 796-818.

617 Huey, R.B., \& Slatkin, M. (1976). Cost and benefits of lizard thermoregulation. Quarterly Review of 618 Biology, 51(3), 363-384.

619 Kearney, M.R., \& Porter, W. (2009). Mechanistic niche modelling: combining physiological and 620 spatial data to predict species' ranges. Ecology Letters, 12(4), 334-350.

621 Kearney, M.R., Munns, S.L., Moore, D., Malishev, M., \& Bull, C.M. (2018). Field tests of a general 622 ectotherm niche model show how water can limit lizard activity and distribution. Ecological 623 Monographs, 88(4), 672-693.

624 Kelley, C.P., Mohtadi, S., Cane, M.A., Seager, R., \& Kushnir, Y. (2015). Climate change in the 625 Fertile Crescent and implications of the recent Syrian drought. Proceedings of the National 626 Academy of Sciences, 112(11), 3241-3246.

627 Ladyman, M., \& Bradshaw, D. (2003). The influence of dehydration on the thermal preferences of 628 the Western tiger snake, Notechis scutatus. Journal of Comparative Physiology B, 173(3), 239-246.

629 Le Galliard, J.-F., Le Bris, M., \& Clobert, J. (2003). Timing of locomotor impairment and shift in 630 thermal preferences during gravidity in a viviparous lizard. Functional Ecology, 17(6), 877-885. 631 Long, R.A., Bowyer, R.T., Porter, W.P., Mathewson, P., Monteith, K.L., \& Kie, J.G. (2014).

632 Behavior and nutritional condition buffer a large-bodied endotherm against direct and indirect 633 effects of climate. Ecological Monographs, 84(3), 513-532. 
634 Lorenzon, P., Clobert, J., Oppliger, A., \& John-Alder, H. (1999). Effect of water constraint on

635 growth rate, activity and body temperature of yearling common lizard (Lacerta vivipara).

636 Oecologia, 118(4), 423-430.

637 Lorioux, S., Lisse, H., \& Lourdais, O. (2013). Dedicated mothers: predation risk and physical

638 burden do not alter thermoregulatory behaviour of pregnant vipers. Animal Behaviour, 86(2), 401639408.

640 Lourdais, O., Dupoué, A., Guillon, M., Guiller, G., Michaud, B., \& DeNardo, D.F. (2017). Hydric

641 "costs" of reproduction: pregnancy increases evaporative water loss in the snake Vipera aspis.

642 Physiological and Biochemical Zoology, 90(6), 663-672.

643 Manenti, R., Denoël, M., \& Ficetola, G.F. (2013). Foraging plasticity favours adaptation to new

644 habitats in fire salamanders. Animal Behaviour, 86(2), 375-382.

645 Marquis, O., Massot, M., \& Le Galliard, J.-F. (2008). Intergenerational effects of climate generate 646 cohort variation in lizard reproductive performance. Ecology, 89(9), 2575-2583.

647 Massot, M., Clobert, J., Lorenzon, P., \& Rossi, J.-M. (2002). Condition- dependent dispersal and 648 ontogeny of the dispersal behaviour: an experimental approach. Journal of Animal Ecology, 71(2), $649253-261$.

650 McGhee, K.E., Pintor, L.M., \& Bell, A.M. (2013). Reciprocal behavioral plasticity and behavioral 651 types during predator-prey interactions. The American Naturalist, 182(6), 704-717.

652 Meylan, S., Dufty, A., \& Clobert, J. (2003). The effect of transdermal corticosterone application on 653 plasma corticosterone levels in pregnant Lacerta vivipara. Comparative Biochemistry and 654 Physiology Part A: Molecular \& Integrative Physiology, 134(3), 497-503.

655 Pinheiro, J., \& Bates, D. (2006). Mixed-effects models in S and S-PLUS. Springer Science \& 656 Business Media.

657 Pintor, A.F.V., Schwarzkopf, L., \& Krockenberger, A.K. (2016). Hydroregulation in a tropical dry658 skinned ectotherm. Oecologia, 182(4), 925-931. 
659 Pirtle, E.I., Tracy, C.R., \& Kearney, M.R. (2019). Hydroregulation. A neglected behavioral response

660 of lizards to climate change? In V. Bels \& A. Russell, Behavior of Lizards: Evolutionary and

661 Mechanistic Perspectives (pp. 343-374). CRC Press.

662 Porter, W.P., Mitchell, J.W., Beckman, W.A., \& DeWitt, C.B. (1973). Behavioral implications of 663 mechanistic ecology. Oecologia, 13(1), 1-54.

664 R Core Team. (2018). R: language and environment for statistical computing. $R$ Foundation for 665 Statistical Computing, 2005; Vienna, Austria.

666 Row, J.R., \& Blouin-Demers, G. (2006). Thermal quality influences effectiveness of

667 thermoregulation, habitat use, and behaviour in milk snakes. Oecologia, 148(1), 1-11.

668 Rozen-Rechels, D., Dupoué, A., Meylan, S., Decencière, B., Guingand, S., \& Le Galliard, J.-F.

669 (2018). Water restriction in viviparous lizards causes transgenerational effects on behavioral anxiety 670 and immediate effects on exploration behavior. Behavioral Ecology and Sociobiology, 72(2), 23.

671 Rutschmann, A., Miles, D.B., Clobert, J., \& Richard, M. (2016). Warmer temperatures attenuate the 672 classic offspring number and reproductive investment trade-off in the common lizard, Zootoca 673 vivipara. Biology Letters, 12(6), 20160101.

674 Sears, M.W., \& Angilletta, M.J. (2015). Costs and benefits of thermoregulation revisited: both the 675 heterogeneity and spatial structure of temperature drive energetic costs. The American Naturalist, 676 185(4), E94-E102.

677 Sears, M.W., Angilletta, M.J., Schuler, M.S., Borchert, J., Dilliplane, K.F., Stegman, M., ...

678 Mitchell, W.A. (2016). Configuration of the thermal landscape determines thermoregulatory 679 performance of ectotherms. Proceedings of the National Academy of Sciences, 113(38), 1059568010600.

681 Stevenson, R.D. (1985). The relative importance of behavioral and physiological adjustments 682 controlling body temperature in terrestrial ectotherms. The American Naturalist, 126(3), 362-386.

683 Therneau, T.M. (2018). coxme: Mixed Effects Cox Models. R package version 2.2-10.

684 Wells, K.D. (2010). The ecology and behavior of amphibians. University of Chicago Press. 
685 Wong, B.B.M., \& Candolin, U. (2015). Behavioral responses to changing environments. Behavioral 686 Ecology, 26(3), 665-673.

687 Zylstra, E.R., Steidl, R.J., Jones, C.A., \& Averill-Murray, R.C. (2013). Spatial and temporal 688 variation in survival of a rare reptile: a 22-year study of Sonoran desert tortoises. Oecologia, 173(1), $689 \quad 107-116$. 
692 Table 1 Summary of individual characteristics before and after the experiment in male (M) and

693 female (F) common lizards from water-restricted (WR) and control groups. Values are average from

694 raw data \pm standard error. Preferred body temperature was calculated from means of multiple

695 records at different times of the day (see methods). Treatment effects on PBT were marginal $\left(F_{1,69}=\right.$

$6963.01, p=0.09)$, whatever the sex (water treatment $\left.\times \operatorname{sex}: F_{1,68}=0.64, p=0.43\right)$.

\begin{tabular}{|l|c|c|c|c|c|}
\hline \multirow{2}{*}{ Trait } & \multirow{2}{*}{ Sex } & \multicolumn{2}{|c|}{ Before experiment } & \multicolumn{2}{c|}{ After experiment } \\
\cline { 3 - 6 } & & Control & WR & Control & WR \\
\hline \multirow{3}{*}{ BM (g) } & $\mathrm{F}$ & $5.4 \pm 0.2$ & $5.5 \pm 0.1$ & $5.9 \pm 0.2$ & $5.6 \pm 0.1$ \\
\cline { 2 - 6 } & $\mathrm{M}$ & $3.9 \pm 0.1$ & $3.9 \pm 0.1$ & $3.9 \pm 0.1$ & $3.7 \pm 0.1$ \\
\hline \multirow{3}{*}{ OSMO (mOsm.kg-1) } & $\mathrm{F}$ & $327 \pm 6$ & $320 \pm 7$ & $340 \pm 6$ & $352 \pm 10$ \\
\cline { 2 - 6 } & $\mathrm{M}$ & $337 \pm 9$ & $335 \pm 7$ & $352 \pm 7$ & $369 \pm 7$ \\
\hline Preferred body & $\mathrm{F}$ & $31.9 \pm 0.2$ & $32.1 \pm 0.2$ & $30.0 \pm 0.1$ & $29.3 \pm 0.1$ \\
\hline \multirow{2}{*}{ temperature $\left({ }^{\circ} \mathbf{C}\right)$} & $\mathrm{M}$ & $34.2 \pm 0.1$ & $34.8 \pm 0.1$ & $33.4 \pm 0.2$ & $33.6 \pm 0.2$ \\
\cline { 2 - 6 } & & & & & \\
\hline
\end{tabular}


700 Figure 1 Effects of chronic water restriction on (A) the intra-individual change in daytime preferred

701 body temperature measured in a neutral thermal gradient before and after the experiment $\left(\Delta \mathrm{T}_{\mathrm{p}}\right),(\mathbf{B})$

702 the body temperature of lizards in the test arenas where water restriction was performed (average

703 from each day) and (C) the thermal accuracy of lizards in their test arenas (average from each day)

704 calculated like the difference between body temperature and preferred body temperature. Points are

705 means and error bars are standard errors from raw data. Curves are best-predicted regression lines

706 from models (see main text) with sex and water-restriction treatment as covariates. F: females, M:

707 males, WR: water-restricted.

709 Figure 2 Proportions of active individuals according to the daytime at day 0 (A), day 2 (B), day 7

710 (C) and day 8 (D) of the experiment. Lines are non-parametric lowess regressions per treatment and

711 sex group. Points are means and error bars are standard errors from raw data. Data from day 0 and

712 day 7 correspond to days without heat stress, whereas data from day 2 and day 8 correspond to days

713 with heat stress simulated from 11:00 to 14:00. Note the graphical shift in activity patterns for

714 water-restricted animals (solid lines) as time of the experiment proceeds. F: females, M: males, WR:

715 water-restricted individuals.

717 Figure 3 Effects of chronic water restriction on (A) the probability of being active vs. inactive, (B)

718 the probability of basking when being active (i.e., basking effort), (C) the probability of selecting a 719 shelter in the warm vs. in the cold side and (D) the probability of selecting a wet shelter in the warm

720 side vs. a dry shelter in warm side, according to the number of days since the start of the

721 experiment. Data and results of best models are reported for measurement days without heat stress

722 between 11:00 and 14:00 to facilitate comparison with Figure 4. Points are means and error bars are

723 standard errors from raw data. Curves are best-predicted regression lines from models (see main 
724 text) with sex and water-restriction treatment as covariates. F: females, M: males, WR: water-

725 restricted. The amplitude of the y-axis (probability) was not presented from 0 to 1 to allow for a

726 better readability of the variations.

728 Figure 4 Effects of chronic water restriction and daily heat stress on (A) the probability of being

729 active vs. inactive, (B) the probability of basking when being active, (C) the probability of selecting

730 a shelter in the warm side vs. in the cold side and (D) the probability of selecting a wet shelter in the

731 warm side vs. a dry shelter in warm side. Data and results of best models are reported for

732 measurement days without heat stress between 11:00 and 14:00 when heat stress was simulated.

733 Grey zones indicate days with heat stress. Points are means and error bars are standard errors from

734 raw data. Curves are best-predicted regression lines from the selected models (see main text) with

735 sex and water-restriction treatment as covariates. In panel $\mathbf{B}$, we observe a decrease of basking

736 effort in water-restricted females during heat stress days that seems to become stronger with the

737 number of days of the experiment. Still, the three-way interaction between water restriction

738 treatment, sex and number of days since the beginning of the experiment was not significant $\left(\chi^{2}=\right.$

$7392.15, \mathrm{df}=1, p=0.14)$. F: females, M: males, WR: water-restricted. 


\section{$741 \quad$ Figure 1}
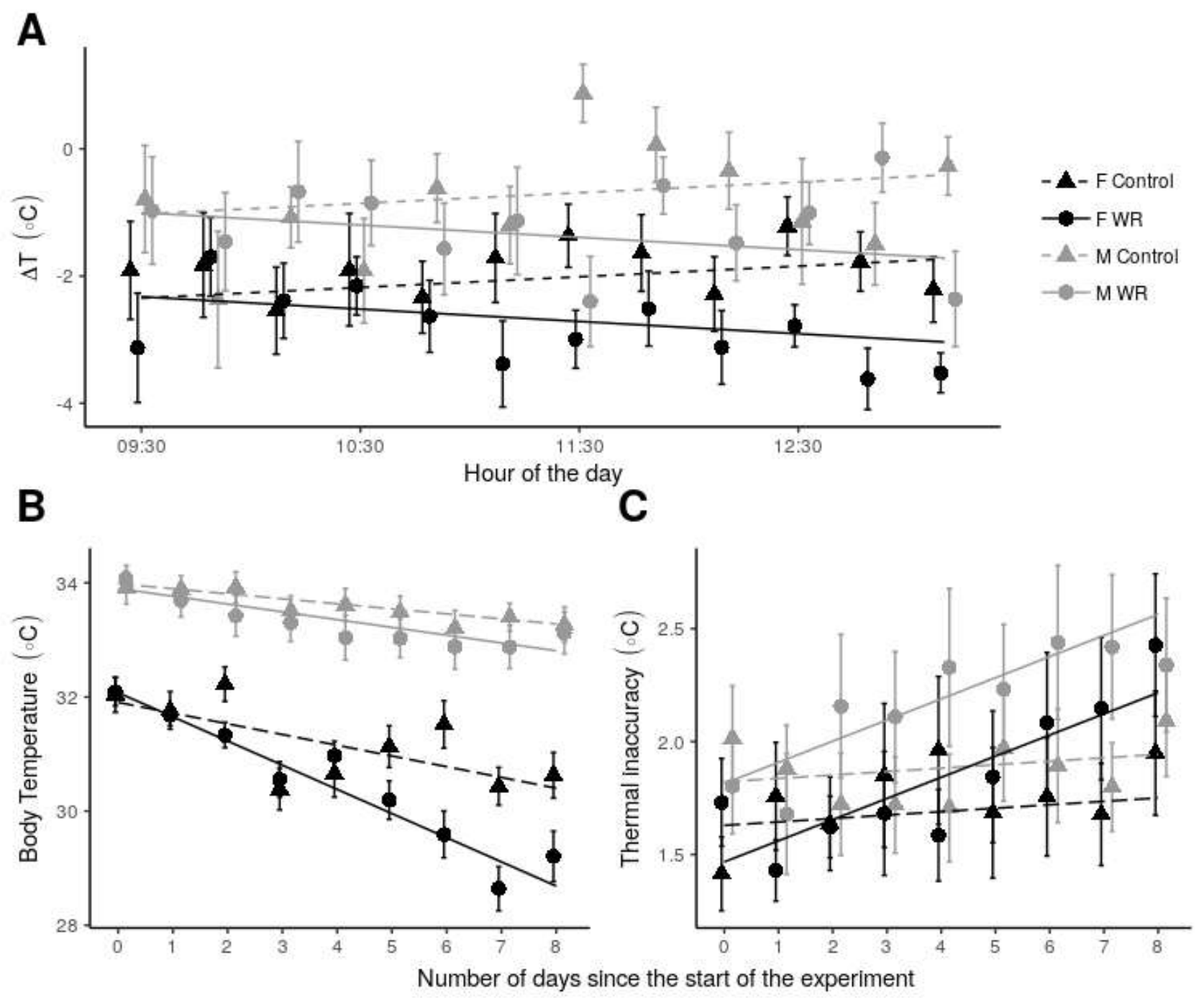


\section{Figure 2}
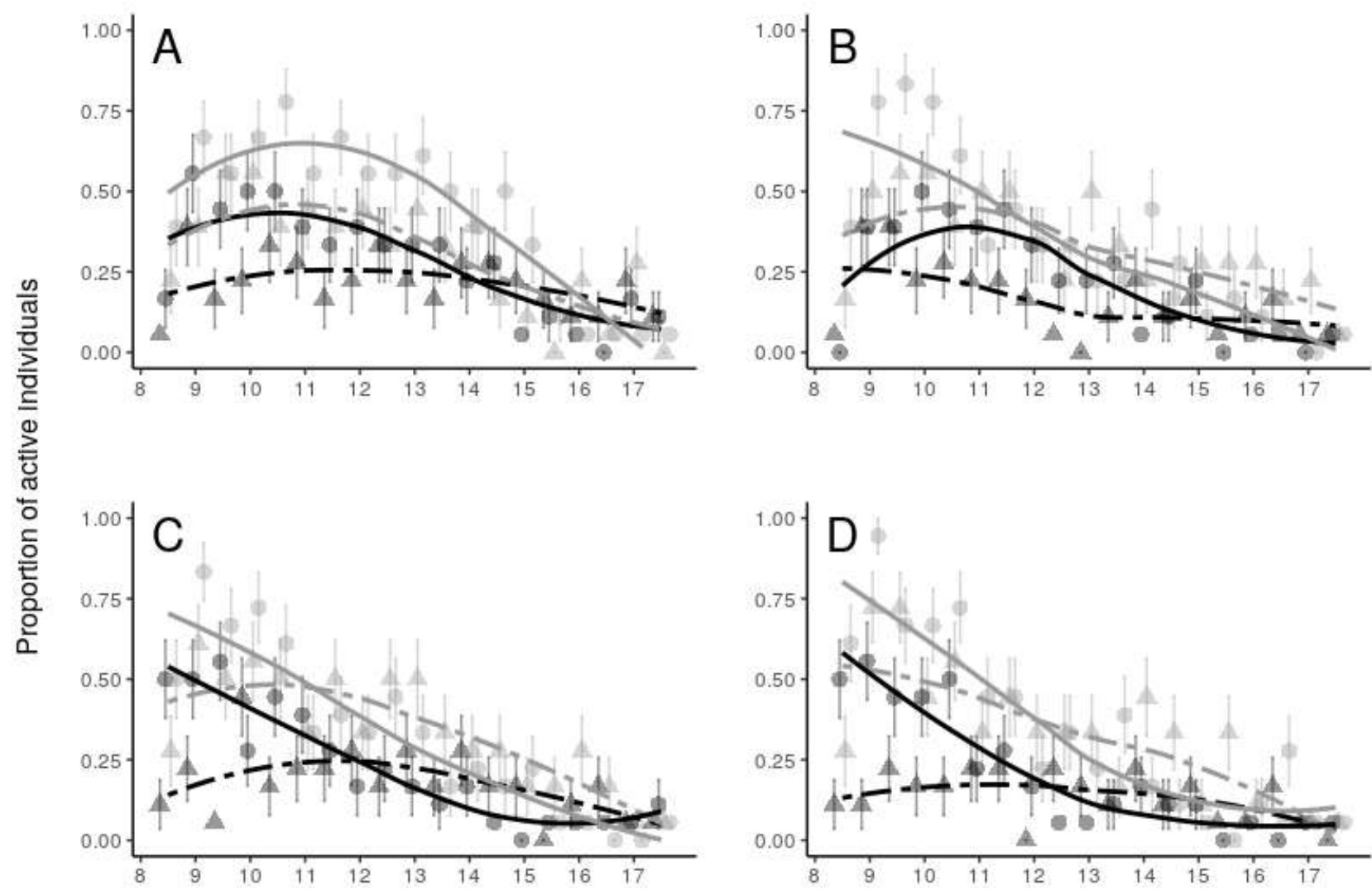

Hour of the day

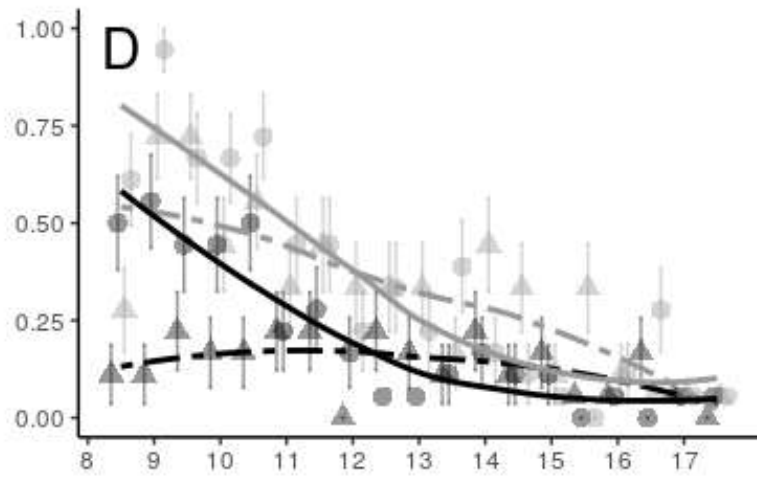

745

746 
747 Figure 3
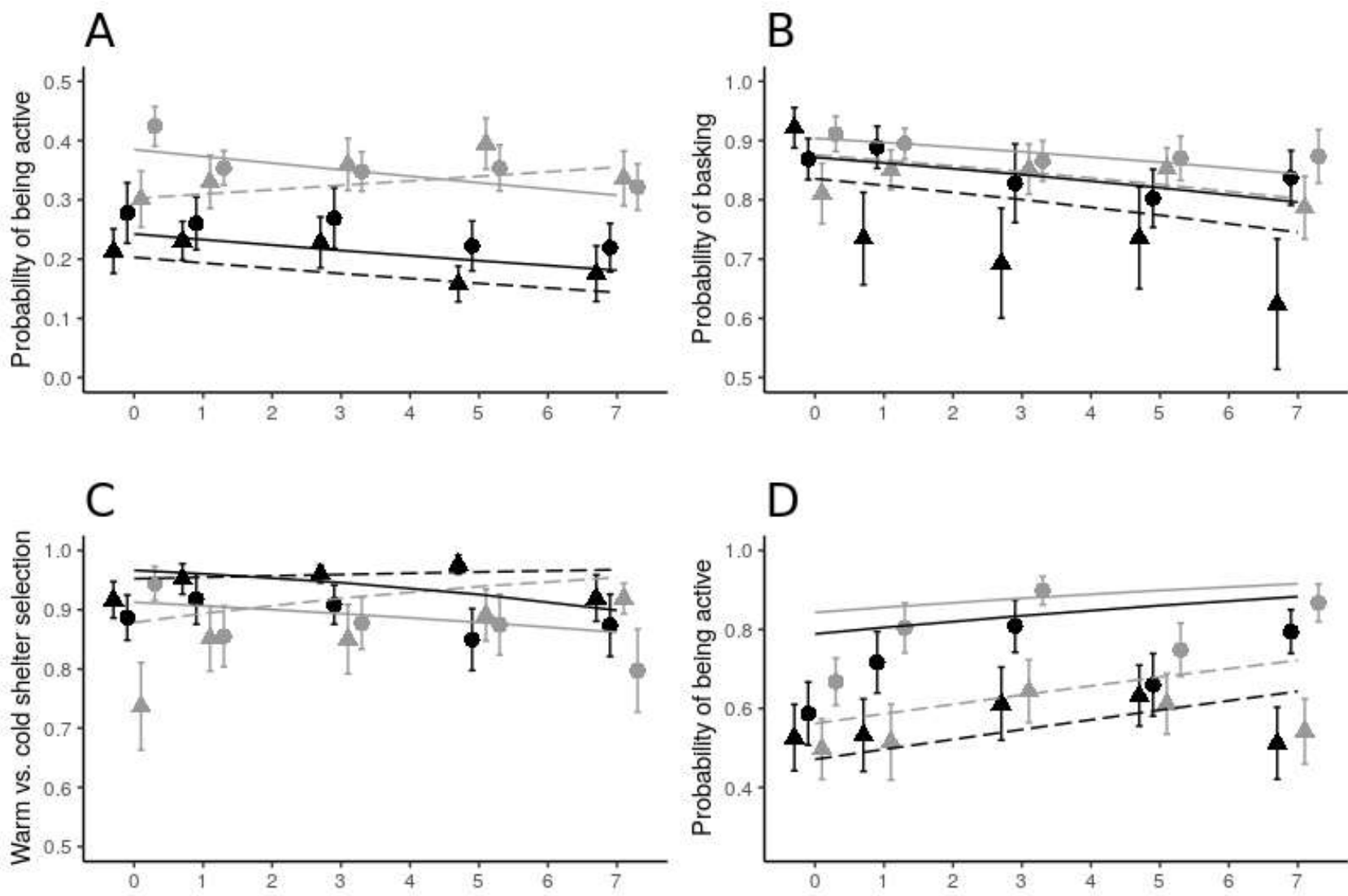

Number of days since the start of the experiment

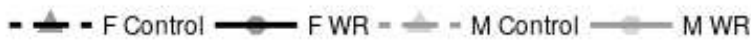



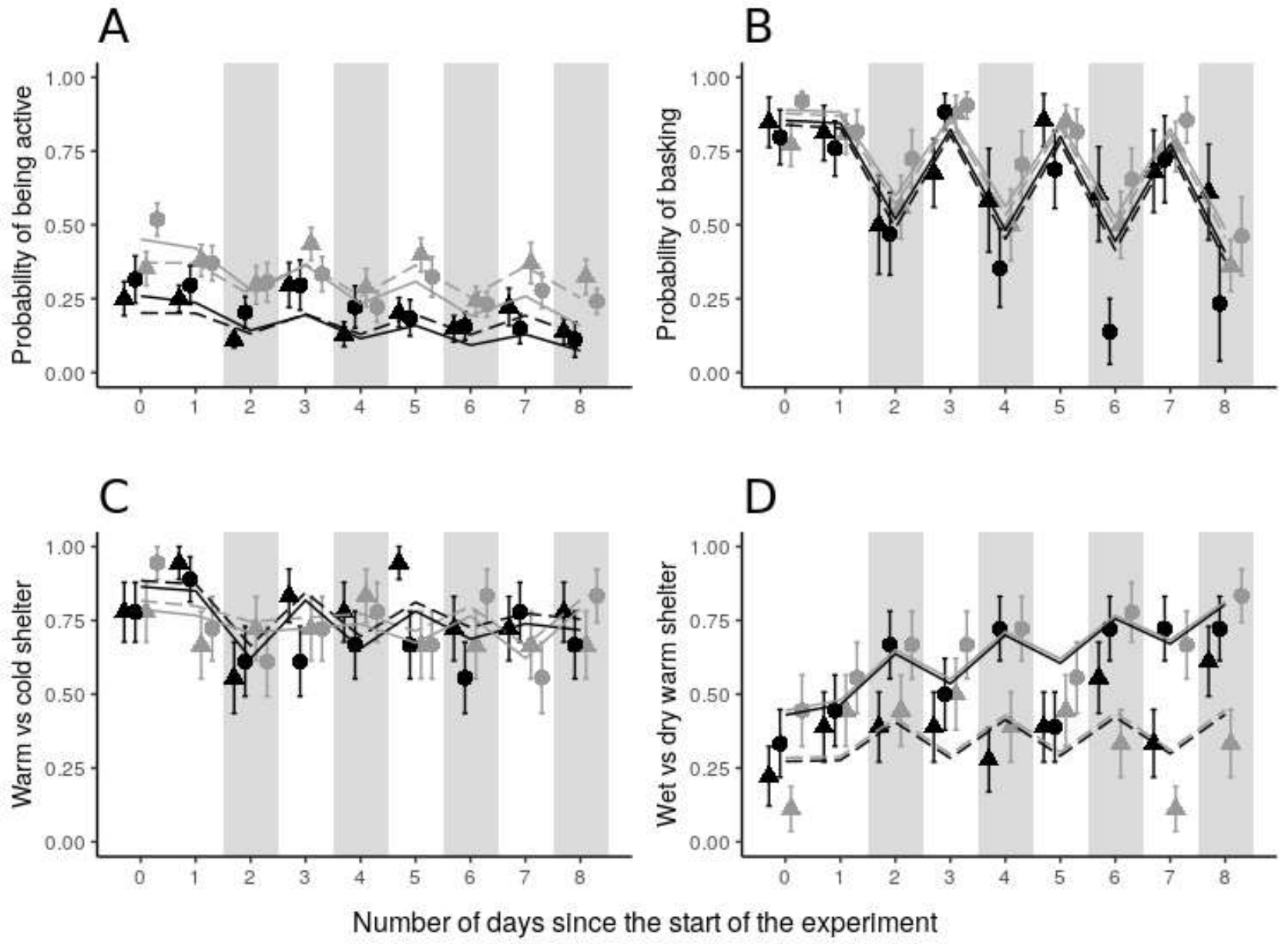

$-\mathbf{A}-\mathrm{F}$ Control $\longrightarrow$ - F WR $-\mathbf{A}-\mathrm{M}$ Control $-\mathrm{e}-\mathrm{M}$ WR 


\section{Supplementary Information 1}

In order to measure the operative temperature of a lizard in micro-habitat, we equipped an experimental arena with 10 temperature probes from 5 HOBO® Pro v2 U23-003 (ONSET Cape Cod, Massachusetts) temperature loggers. Each probe was fitted inside a copper tube $(1 \mathrm{~cm}$ diameter, $6 \mathrm{~cm}$ long) painted in a mix of brown and green color and with black and light lines in order to mimic the reflectance properties of a common lizard. The probe was fixed inside the tube without touch the copper by using pipette tips that were cut at the right diameter. We measured the operative temperature inside and on top of each shelter as well as in the middle of the terrarium every 5 minutes. We averaged this temperature over 30 minutes periods to have calculate the average operative temperature in the environment (Figure S1).

We also placed in the center of each arena a temperature and humidity data logger (iButton DS1923, Maxim Integrated, San Jose, California). We measured average temperature and relative humidity every 5 minutes (see Figure S2).

\section{Figure S1}

Daily variation of operative temperature during days without (A and $B$ ) and with $(C$ and $D)$ heat stress between 11:00 and 14:00. A and $\mathrm{C}$ are record from shelters on the hot side shelters and middle of the arena i, B and D are for cold side shelters. Jittered points correspond to raw operative temperature values, lines are prediction from a smooth loess regression.

\section{Figure S2}

Boxplot of the temperature $(\mathrm{A})$ and relative humidity $(\mathrm{H})$ measures in the 13 terraria. Boxes represent the range from the $25 \%$ to the $75 \%$ quantile. Bold lines in the boxes are for the median value. Points are marginal value from the calculated distribution. 
Figure S1

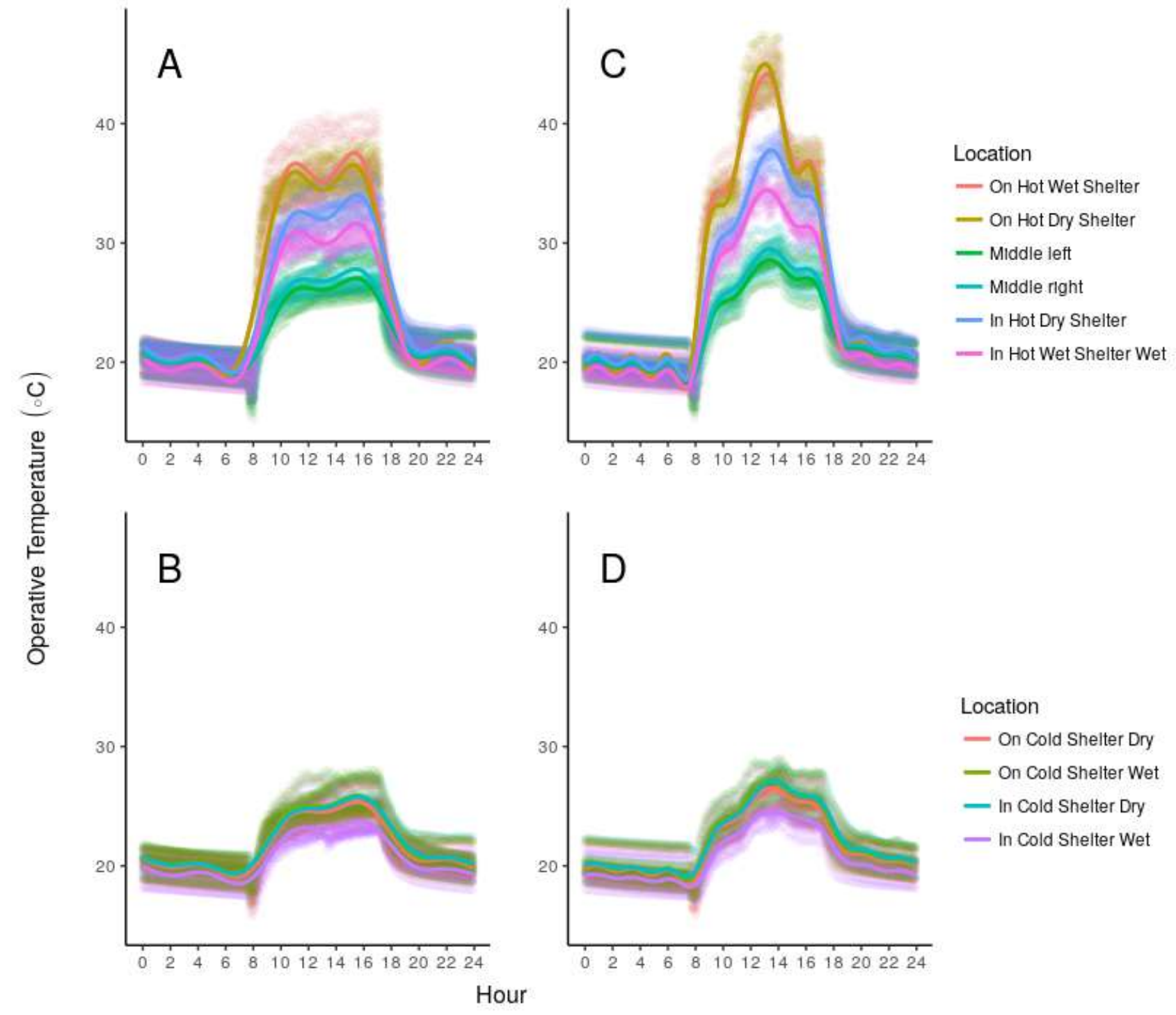


Figure S2
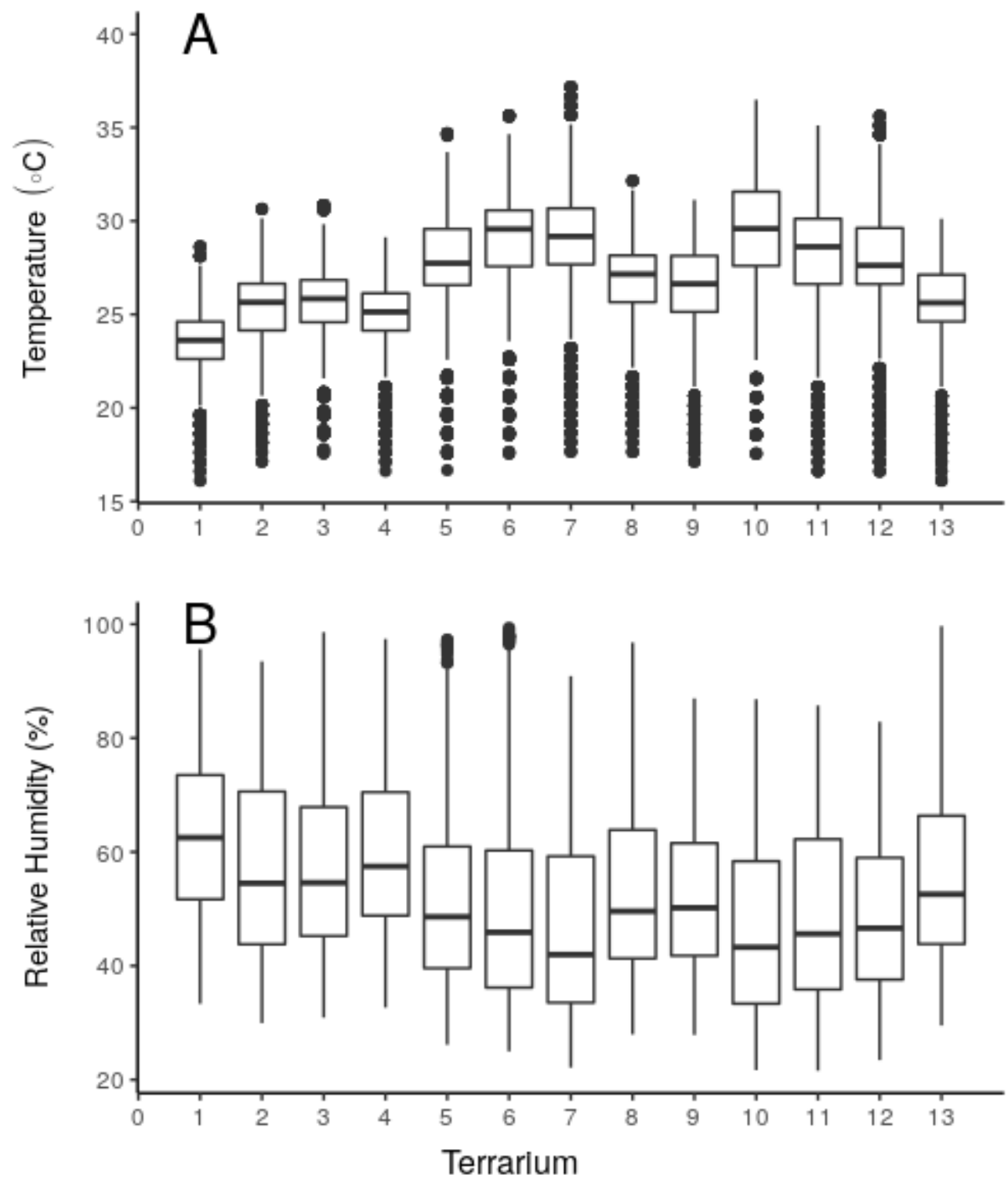


\section{Supplementary In formation 2}

From May $6^{\text {th }}$ to May $9^{\text {th }} 2019$, we ran the same experimental conditions in two experimental terraria. Between 11:00 and 14:00 of May $7^{\text {th }}$ and May $9^{\text {th }}$ we implemented a heat stress. We measured air relative humidity and temperature every 5 minutes in each shelter by fixing a thermohygrochron on the shelter wall above the sponge (iButton DS1923, Maxim Integrated, San Jose, California). We calculated water vapor pressure for each log following Tieleman et al. (2002) methods.

Tieleman BI, Williams JB, Buschur ME. 2002. Physiological adjustments to arid and mesic environments in larks (Alaudidae). Physiological and Biochemical Zoology. 75(3):305-313. doi:10.1086/341998.

Figure S3 Chronology of the experiment for one experimental group.

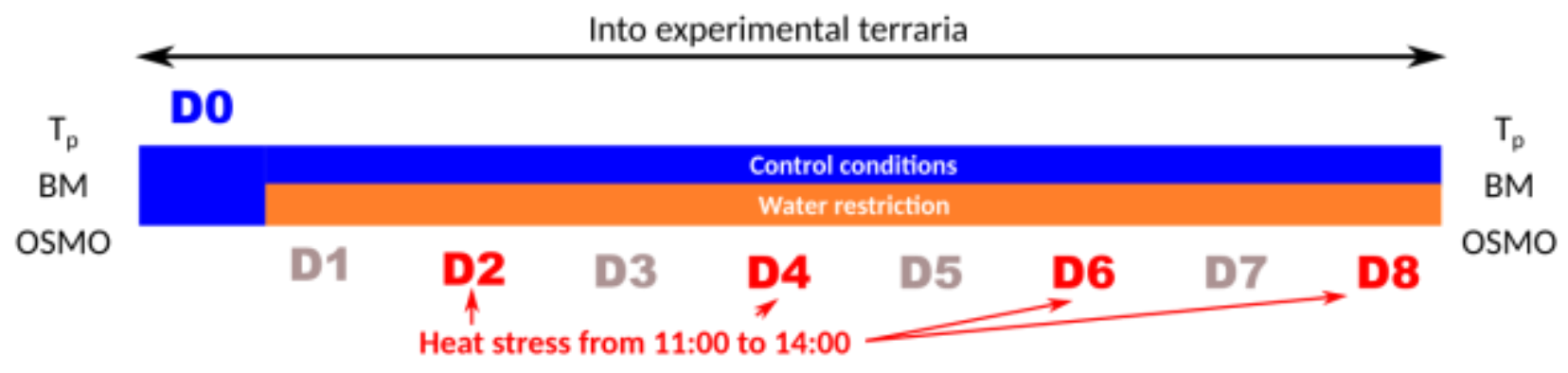


4 Table S1 Description of the results of the best models explaining activity, basking, selection of hot 5 vs. cold shelters and selection of wet hot vs. dry hot shelters with the effects of heat stress. With $\chi^{2}$ 6 the value of the chi-square test, $\mathrm{df}$ the number of degree of freedom associated and $p$ is the two-

7 sided $\mathrm{p}$ value.

8 HS I: heat stress treatment;WR: water restriction treatment.

\begin{tabular}{|c|c|c|c|c|}
\hline Behavior & Fixed effect & $\chi^{2}$ & df & $p$ \\
\hline \multirow{3}{*}{ Activity } & HS & 33.95 & 1 & $<0.0001$ \\
\hline & Sex & 11.41 & 1 & 0.0007 \\
\hline & $\mathrm{WR} * D_{\exp }$ & 13.85 & 1 & 0.0002 \\
\hline \multirow{2}{*}{ Basking } & $D_{\exp }$ & 6.61 & 1 & 0.01 \\
\hline & HS & 91.33 & 1 & $<0.0001$ \\
\hline \multirow{2}{*}{$\begin{array}{l}\text { Hot vs. cold } \\
\text { shelter }\end{array}$} & $\mathrm{HS} * D_{\exp }$ & 5.55 & 1 & 0.02 \\
\hline & $\mathrm{HS} * \mathrm{Sex}$ & 6.07 & 1 & 0.01 \\
\hline \multirow{3}{*}{$\begin{array}{l}\text { Wet vs. dry hot } \\
\text { shelter }\end{array}$} & HS & 8.83 & 1 & 0.003 \\
\hline & WR & 19.14 & 1 & $<0.0001$ \\
\hline & $D_{\exp }$ & 5.01 & 1 & 0.03 \\
\hline
\end{tabular}




\section{Supplementary Information 3}

11 In order to evaluate possible avoidance behaviors between the two individuals in the same

12 terrarium, we counted the number of times individuals were in the same shelter and the number of

13 times both individuals were in a shelter but not the same one. We then compared the probability of

14 being together vs. being separated in a shelter according to the water treatment with a MANOVA

15 fitted with a generalized linear mixed model with a binomial error, also adding the group as a fixed

16 effect and the couple as a random effect.

17 The treatment did not explained significantly variations in the probability that two individuals

18 stayed together in the same shelter, we however highlighted a tendency that water-restricted

19 individuals had higher probability to be together in the same shelter than separated $\left(\chi^{2} 1,5=3.6, p=\right.$

200.06 , estimate \pm SE: $0.38 \pm 0.20$ ) compared to control individuals that had the same probability to

21 be together or separated $(0.11 \pm 0.20)$. It seems that in the case of water-restriction, individuals

22 remained together mainly in warm and wet shelters (Figure S4). 
23 Figure S4 Number of times we observed individuals together and in what shelter when both of 24 them were in a shelter at the same time. Colors represent the shelter selected by the female (same as 25 the males when together). Toge. $=$ together; sep. $=$ seperated.

26

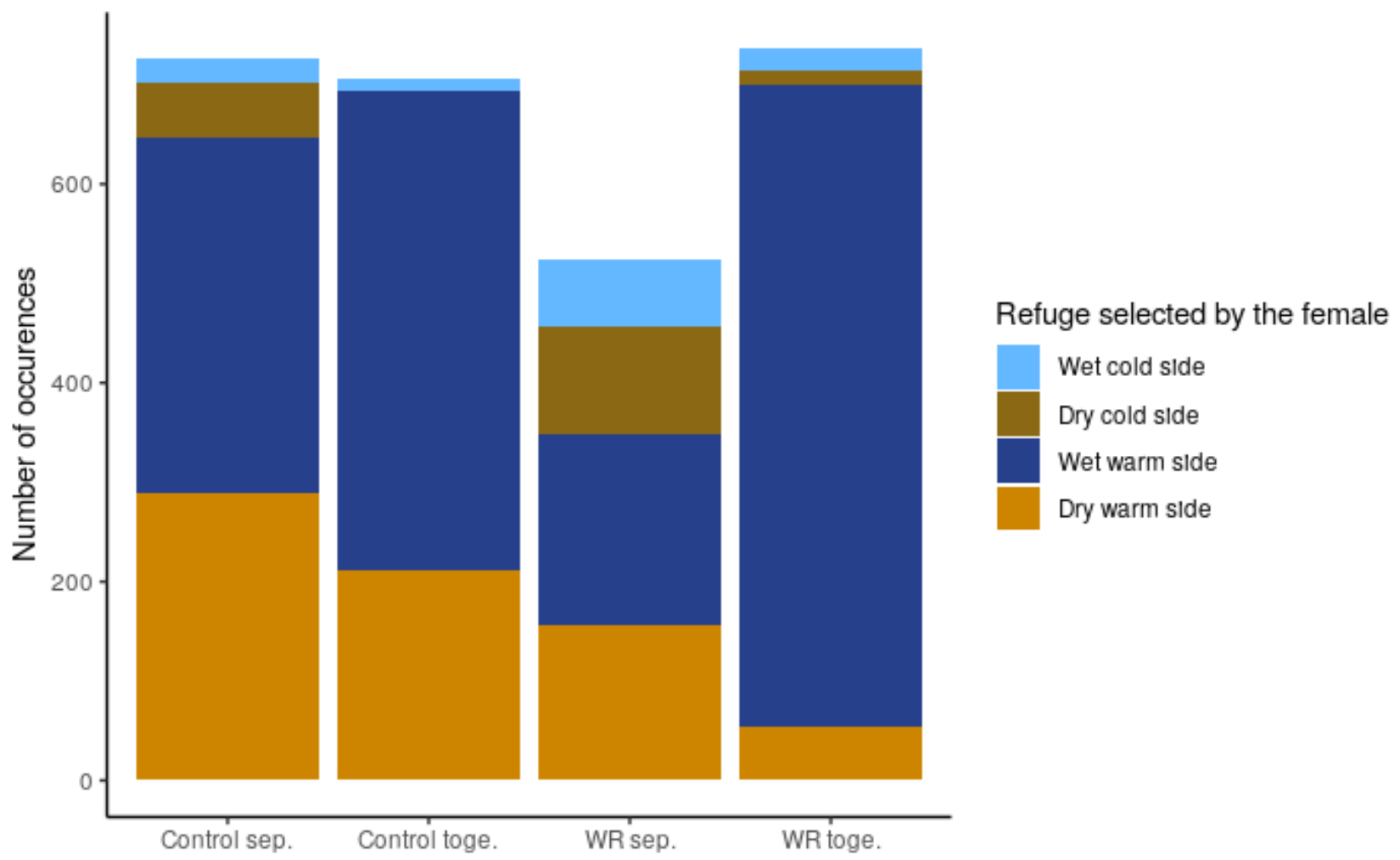

